\title{
Case Study of Remaining Service Life Assessment of a Cooling Water Intake Concrete Structure in Indonesia
}

\author{
M. Sigit Darmawan, Ridho Bayuaji, N. A. Husin, and R. B. Anugraha \\ Civil Engineering Diploma Program, Institut Teknologi Sepuluh Nopember (ITS), Surabaya 60111, Indonesia \\ Correspondence should be addressed to M. Sigit Darmawan; msdarmawan@ce.its.ac.id
}

Received 8 August 2014; Revised 10 October 2014; Accepted 10 October 2014; Published 11 November 2014

Academic Editor: Andreas Kappos

Copyright (C) 2014 M. Sigit Darmawan et al. This is an open access article distributed under the Creative Commons Attribution License, which permits unrestricted use, distribution, and reproduction in any medium, provided the original work is properly cited.

\begin{abstract}
This paper deals with the assessment of remaining service life of a cooling water intake concrete structure (CWICS) subjected to corrosion due to chloride attacks. Field and laboratory tests were performed to determine the current existing condition of the structure. Both destructive and nondestructive tests were employed to obtain the parameter needed for the assessment. Based on the current condition and test results, structural analysis was carried out and the remaining safety factor of CWICS was determined. From the analysis, it was found that most concrete elements of CWICS had safety factor greater than unity and might fulfil its intended service life up to the year 2033. However, fewer elements require immediate strengthening to extend their service life.
\end{abstract}

\section{Introduction}

Corrosion of reinforcing steel due to chloride attack is considered to be the primary cause of concrete deterioration of reinforced concrete structure [1]. This factor combined with poor practice in detail design, bad supervision, and bad construction execution lead to early deterioration of concrete structures. Concrete structures built $30-40$ years ago often do not comply with the present day and more modern code requirement for durability. For example, most of the present day concrete codes specify that the minimum cover for concrete structures built in marine environment is $65 \mathrm{~mm}$ [2], whereas the corresponding minimum concrete cover during that time is around $50 \mathrm{~mm}$. Furthermore, theoretical foundation of chloride penetration in concrete structure was not yet fully developed and well understood at that time. This lack of knowledge and understanding on concrete deterioration mechanism lead to nonintended faulty concrete practices. Therefore, it is not surprising that older concrete structures often has durability problem before their design life has expired.

It is also expected for concrete structures built in a tropical country such as Indonesia to have higher corrosion rate than that of concrete structures built in temperate or cold region [3]. This higher corrosion rates are caused by higher average temperature and higher humidity experience by concrete structures along the years. Furthermore, workmanship and construction practice in Indonesia is not as good as those in a developed country. All of these factors may lead to early deterioration of concrete structures and shorten the service life of concrete structure.

\section{Case Study}

This paper presents a study of remaining life assessment [4] of cooling water intake concrete structure (CWICS) at Indonesia. The study is comprised of field and laboratory test and followed by analytical study. CWICS has been in service for 19 to 33 years and subject to continues chloride attack from nearby sea. Therefore, it almost reaches its design service life of 30 years. In addition, part of CWICS also subjects to high temperature from the discharge cooling water from the factory. This higher temperature can increase corrosion rate of steel rebar in concrete [5]. All of these conditions may shorten the service life of CWICS and endanger the factory operation. CWICS has an important role in gas production factory as it supplies cooling sea water needed by the factory.

At present, some parts of CWICS have shown some signs of damages, such as staining, rusting, cracking, spalling, 


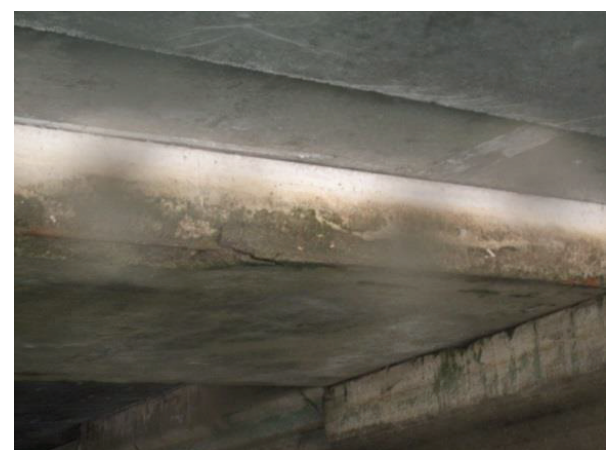

FIGURE 1: Cracking of concrete plate (slab) of CWICS.

and delamination of concrete, see Figure 1. These damages indicate that the chlorides may have already penetrated concrete cover, reached rebar level, and accumulated to threshold level chloride concentration to initiate corrosion. The corrosion may have reduced rebar cross-section and lead to a reduced strength capacity of some structural elements of CWICS. If this condition is not rectified soon, it may endanger the whole structure of CWICS and shut down the factory operation. The shutdown of the factory can lead to significant loss of revenue to factory owner.

The purpose of this study can be summarized as follows:

(i) determine current existing condition of CWICS;

(ii) determine remaining life of CWICS;

(a) determine the safety factor of CWICS at year 2013;

(b) determine the safety factor of CWICS at year 2033.

\section{Structural Configuration of Cooling Water Intake Concrete Structure}

Cooling water intake concrete structure (CWICS) is made of concrete structure supported by steel piles. The concrete structure of CWICS comprises plate (slab), beam, and wall elements. A steel frame is installed on the top of CWICS for a crane operation (see Figure 2). In addition, a number of machines for pumping sea water are stationed on top of the concrete structure. Most of these machines run for 24 hours without stopping. CWICS consists of 4 trains, which has almost similar structural configuration. These are trains A/B, C/D, E/F, and G/H, built in 1977, 1982, 1987, and 1995, respectively. These trains were built by different contractors.

\section{Methodology}

To determine remaining service life of CWICS, the current condition of CWICS needs to be investigated and rate of deterioration needs to be determined. The ultimate goal of this study was to determine whether CWICS can fulfill its intended service life up to 2033 without strengthening. To

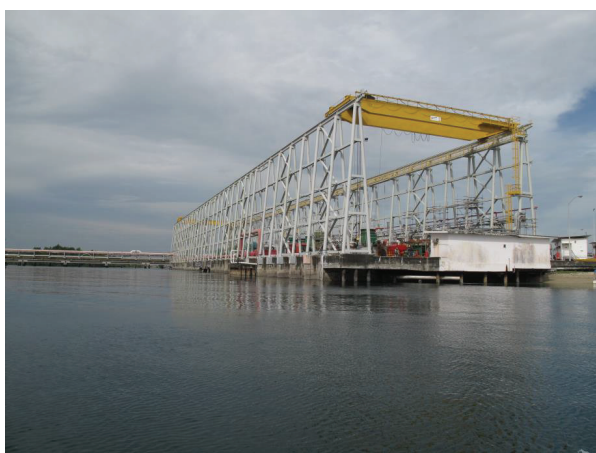

Figure 2: Front view of CWICS.

achieve this goal, the following steps and tests were employed in this study.

(i) Collect information regarding design criteria from available document and as-built drawing and any changes might occur during service period.

(ii) Determine current concrete density and concrete compressive strength of CWICS.

(a) Compression test of core-drilled concrete sample.

(b) Ultrasonic pulse velocity (UPV) test.

(c) Hammer test.

(d) Porosity test.

(iii) Determine carbonation depth.

(a) Phenolphthalein test.

(iv) Determine yield strength of rebar and remaining steel rebar thickness.

(a) Tension test of rebar samples taken from coredrilled concrete samples.

(b) Thickness loss measurement of corroded rebar.

(v) Determine chloride content and $\mathrm{pH}$ of the concrete at different depth.

(a) Chloride content test from core-drilled concrete samples.

(b) $\mathrm{pH}$ test.

(vi) Determine chloride and sulphate contents of seawater.

(vii) Determine probability of corrosion of rebar.

(a) Half-cell potential measurement.

(viii) Structural and load modeling of CWICS using available finite element. program to determine the internal forces. 
(ix) Determine rate of concrete deterioration.

(a) Concrete cover depth measurement.

(x) Determine present capacity of structural element of CWICS.

(xi) Determine remaining service life of CWICS.

At present paper, only concrete structure of CWICS is considered. Steel piles that supported CWICS will be discussed in another study. It must be mentioned here that, during field tests, factory operation must not be interrupted. Further, safety measure in the studied area was very tight and only limited access was given to do the field test. Therefore, the number and the location of tests performed were rather limited. To compensate this deficient, data interpretation of the tests was combined with engineering judgment to predict remaining service life of CWICS. Due to limited number of data obtained from this study, only deterministic approach was discussed in this paper.

4.1. Determine Current Concrete Condition of CWICS. Information regarding the design compressive concrete strength of CWICS can be found in the available as-built drawing and document specification. The specified concrete strength was $28 \mathrm{MPa}$ with a maximum water-cement ratio of 0.4 and used type II cement. This concrete strength is slightly lower than the present day minimum concrete strength requirement for marine environment of $35 \mathrm{MPa}$. However, the actual compressive strength achieved during construction was not well documented. Therefore, this data must be obtained by performing field and laboratory test. Four different tests were used to estimate current concrete condition of CWICS. These included compression test of core-drilled concrete sample, hammer test, UPV test, and porosity test. The most accurate method to determine concrete strength is compression test of core-drilled concrete sample. However, this destructive method is very expensive to perform and create permanent defect at the existing structure (see Figure 3). Therefore, this method was combined with nondestructive test, such as hammer and UPV test to get more data for concrete strength indication and homogeneity. Hammer and UPV tests were performed for each location of core-drilled concrete sample and other locations. If the number of data is sufficient, a correlation chart between these tests and compressive strength can be derived. Using this chart, the concrete strength can then be inferred both from hammer and UPV tests. However, as shown later in the next section, a good correlation factor was not always obtained between these tests due to a number of reasons.

Table 1 gives the number of concrete core-drilled samples for each train. This table shows that more samples are taken from older train than newer one. This approach was employed as older train has shown more sign distress than newer train. The location of core-drilled sample at train A/B is shown in Figure 4. A similar pattern of sampling was also used for other trains. To avoid rebar in the concrete, the location of core-drilled was first checked using rebar detector before any drilling operation commenced. However, out of

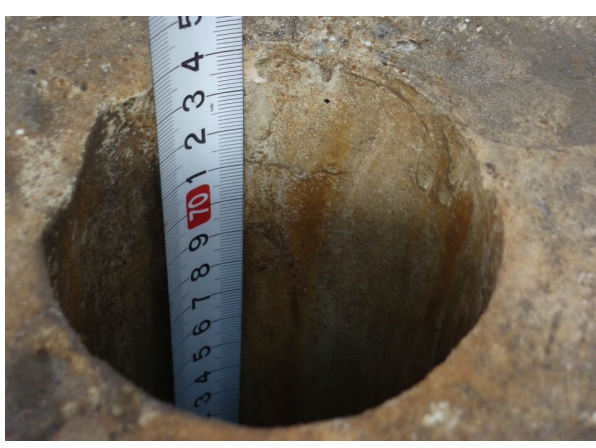

Figure 3: Core-drilled sample.

TABLE 1: Number of concrete core-drilled sample.

\begin{tabular}{lc}
\hline Train & Numbers \\
\hline A/B & 5 \\
C/D & 4 \\
E/F & 3 \\
G/H & 3 \\
\hline Total & 15 \\
\hline
\end{tabular}

TABLE 2: Compressive strength of core-drilled sample.

\begin{tabular}{lccc}
\hline No. & Code & Location & $\begin{array}{c}\text { Compressive } \\
\text { strength }\left(\mathrm{kg} / \mathrm{cm}^{2}\right)\end{array}$ \\
\hline 1 & Core 1 & Train A/B & 222.13 \\
2 & Core 2 & Train A/B & 246.63 \\
3 & Core 3 & Train A/B & 279.66 \\
4 & Core 6 & Train C/D & 408.35 \\
5 & Core 8 & Train C/D & 401.70 \\
6 & Core 9 & Train C/D & 377.76 \\
7 & Core 10 & Train E/F & 373.76 \\
8 & Core 11 & Train E/F & 351.93 \\
9 & Core 12 & Train E/F & 397.65 \\
10 & Core 14 & Train G/H & 411.01 \\
\hline
\end{tabular}

fifteen core-drilled samples, only ten samples were successfully compression tested and five samples were broken during the drilling process. The broken samples were examined and it was found that cracks were formed in these samples. The core-drilled samples were obtained from the top of CWICS as the access from the other side was very limited and the factory must operate at all times without stopping. The compressive strength of core-drilled samples is given in Table 2.

Table 2 shows that the compressive strengths of coredrilled samples of train $\mathrm{A} / \mathrm{B}$ are lower than the compressive strength of core-drilled samples from the other trains. This result may indicate that the concrete at this oldest train has already experienced more strength degradation than concrete at the other trains. The concrete strength at train $\mathrm{A} / \mathrm{B}$ is lower than the present day minimum concrete strength requirement for marine environment (i.e., $350 \mathrm{~kg} / \mathrm{cm}^{2}$ ) such as stipulates in [2] and also lower than the specified concrete 


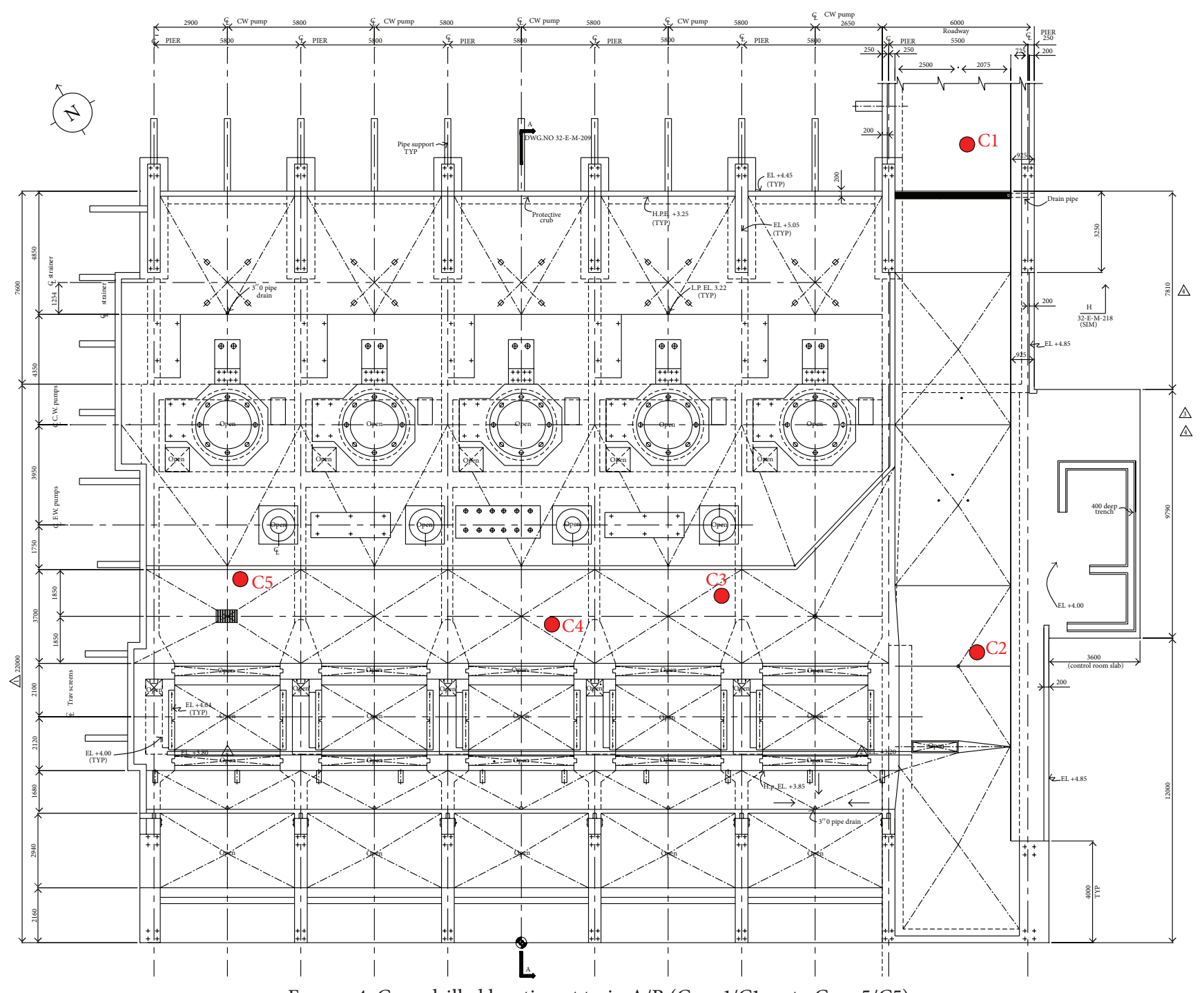

Figure 4: Core-drilled location at train A/B (Core 1/C1 up to Core 5/C5).

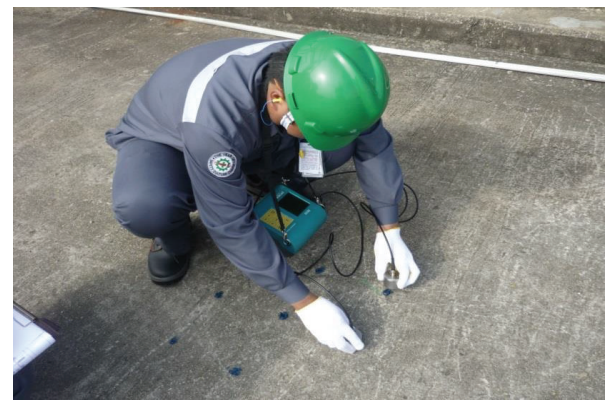

Figure 5: UPV test at train A/B.

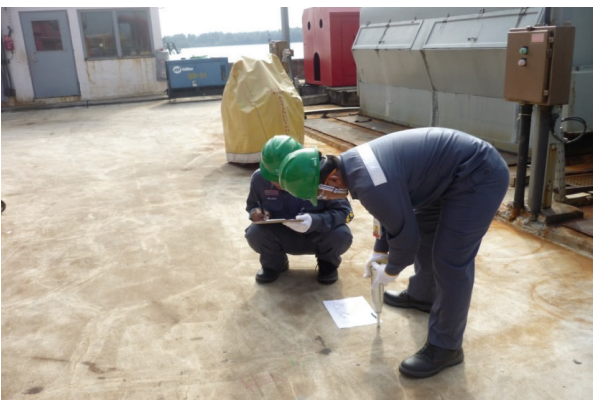

Figure 6: Hammer test at train A/B. strength of $280 \mathrm{~kg} / \mathrm{cm}^{2}$ as found in as-built drawing. By comparison, the highest compressive strength was obtained at the newest train $\mathrm{G} / \mathrm{H}$ at $411.01 \mathrm{~kg} / \mathrm{cm}^{2}$. However, only one coredrilled sample has been successfully tested for this train. In addition to concrete core drill, UPV and hammer tests were performed as shown in Figures 5 and 6. The location of these tests can be seen in Figures 7 and 8, respectively.
Table 3 shows the ultrasonic velocity and its corresponding compressive strength for all trains. This table shows that almost all ultrasonic velocities in the concrete fall below $3000 \mathrm{~m} / \mathrm{s}$, except the ultrasonic velocity of cores 3 and 8 . Based on [6], these low ultrasonic velocities can be classified as doubtful. These low readings of ultrasonic velocity are possibly due to discontinuity that presents in the concrete 


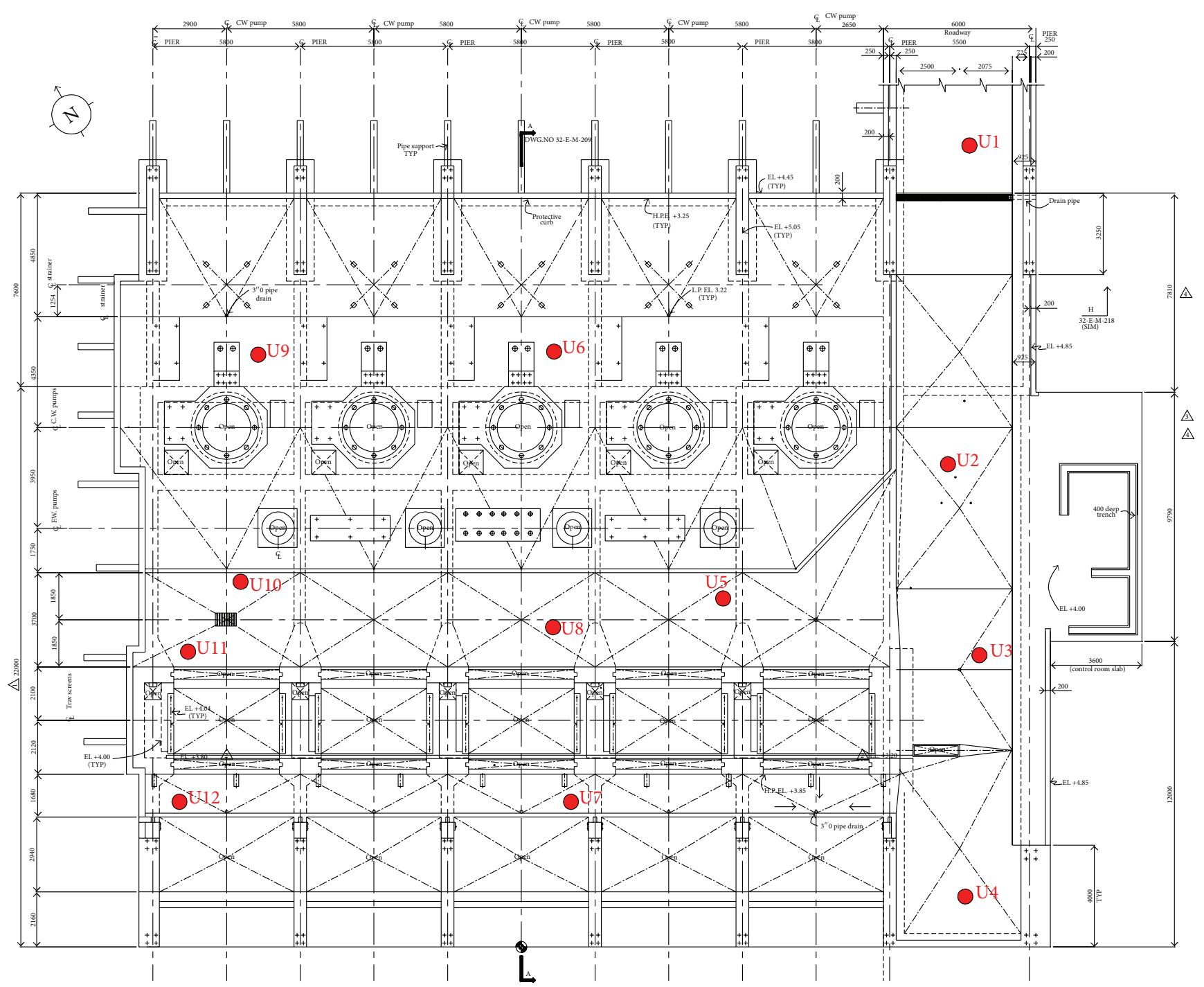

FIgURE 7: UPV test location at train A/B.

plate (slab) of CWICS. After a close examination of coredrilled samples in the laboratory, it was found that a $20 \mathrm{~mm}$ nonshrinking grouting material was laid on top of concrete plate to give additional protection against chloride environment. Because this material and the old concrete below have different properties, discontinuity presents between them. This discontinuity reduces the ultrasonic velocity in the concrete. The ultrasonic pulse may be diffracted around the discontinuities, therefore increasing the travel path and travel time [7].

Table 3 indicates that core 1 drilled at train $\mathrm{A} / \mathrm{B}$ gives the lowest ultrasonic velocity of $1830 \mathrm{~m} / \mathrm{s}$. This lowest value corresponds with its lowest compressive strength of $222.13 \mathrm{~kg} / \mathrm{cm}^{2}$. Similar trend is also found for train C/D where low compressive strength corresponds with low ultrasonic velocity. However, this trend does not apply for train E/F where low compressive strength gives high ultrasonic velocity. Table 3 also shows that the highest ultrasonic velocity of $3232 \mathrm{~m} / \mathrm{s}$ is found at core 8 with its corresponding compressive strength of $279.66 \mathrm{~kg} / \mathrm{cm}^{2}$. As each train was built in different years and used different concrete mixes, correlation chart between UPV and compression strength for each train was derived separately. The correlation chart is shown in Figures 9, 10, and 11 for train $\mathrm{A} / \mathrm{B}, \mathrm{C} / \mathrm{D}$, and $\mathrm{E} / \mathrm{F}$, respectively.

Figures 9 to 11 show that the best correlation between ultrasonic velocity and compressive strength is found for samples taken at train $\mathrm{A} / \mathrm{B}$, with a correlation factor $(R)$ of 0.997. On the contrary, Figure 11 shows an opposite trend between these two tests at train E/F, where the highest ultrasonic velocity gives a lower strength. Again this result confirms that nondestructive test results should not be used solely without destructive test as it may lead to wrong interpretation.

Figure 12 shows a correlation chart between hammer and compressive strength at train $\mathrm{C} / \mathrm{D}$. It gives a reasonable correlation factor $(R)$ of 0.72089 . However, if all hammer tests for all trains are combined in one chart, the correlation factor between hammer and compressive strength drops to 0.19884 


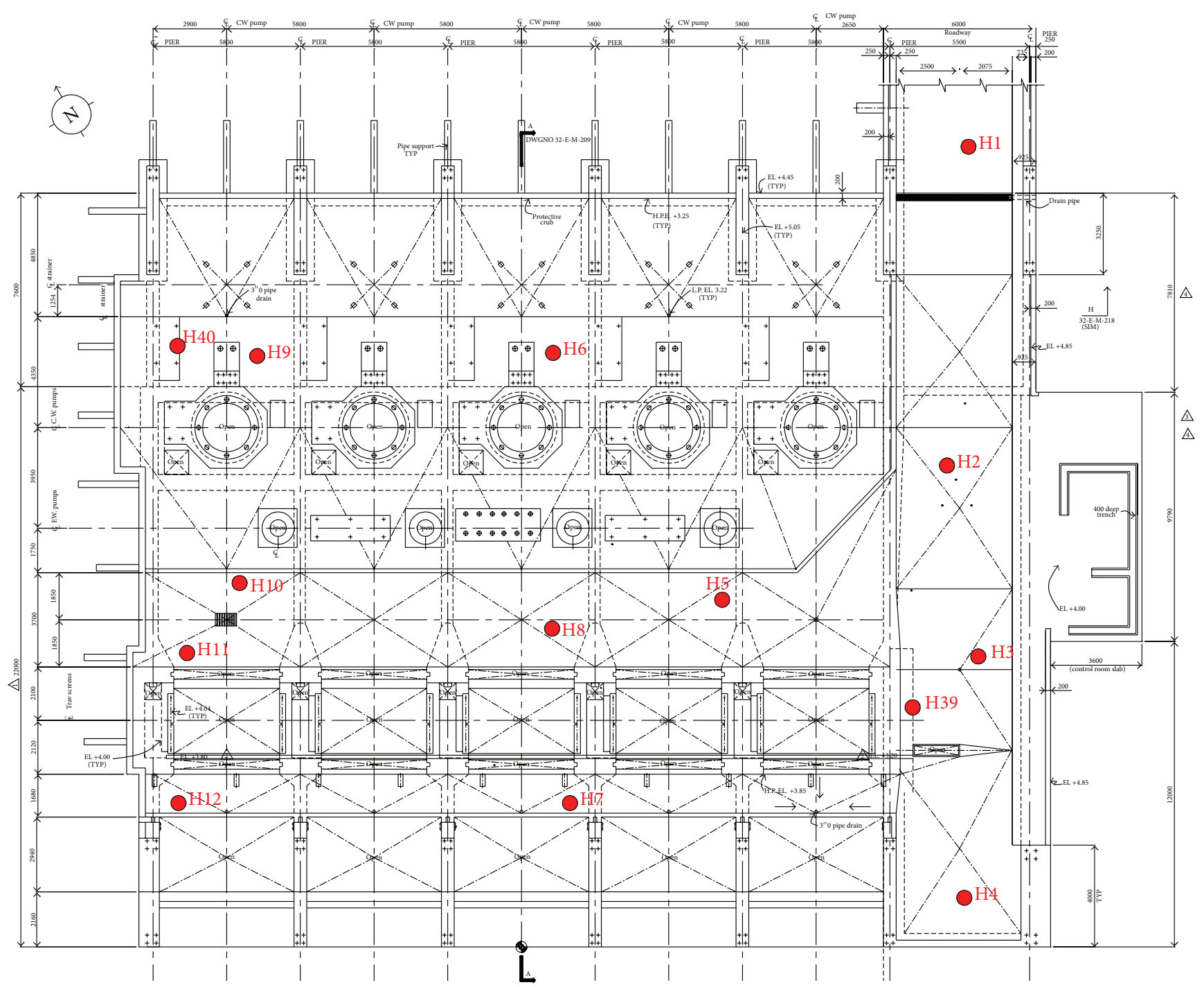

FIGURE 8: Hammer test location at train A/B.

TABLE 3: Compressive strength and ultrasonic velocity of coredrilled samples.

\begin{tabular}{lcccc}
\hline Number Code & Location & $\begin{array}{c}\text { Compressive } \\
\text { strength }\left(\mathrm{kg} / \mathrm{cm}^{2}\right)\end{array}$ & $\begin{array}{c}\text { Ultrasonic } \\
\text { velocity }(\mathrm{m} / \mathrm{s})\end{array}$ \\
\hline 1 & Core 1 & Train A/B & 222.13 & 1830 \\
2 & Core 2 & Train A/B & 246.63 & 2338 \\
3 & Core 3 & Train A/B & 279.66 & 3232 \\
4 & Core 6 & Train C/D & 408.35 & 2420 \\
5 & Core 8 & Train C/D & 401.70 & 3002 \\
6 & Core 9 & Train C/D & 377.76 & 2413 \\
7 & Core 10 & Train E/F & 373.76 & 1842 \\
8 & Core 11 & Train E/F & 351.93 & 2263 \\
9 & Core 12 & Train E/F & 397.65 & 2008 \\
10 & Core 14 & Train G/H & 411.01 & 2610 \\
\hline
\end{tabular}

as shown in Figure 13. It must be mentioned herein that, before hammer tests were performed, the hammer equipment was calibrated first using standard anvil from the manufacturer. Further, the concrete surface was first grinded to obtain flat surface. However, the rebound numbers obtained during the test were lower than those available in the literature and also gave lower correlation factor between hammer and compressive strength [8]. One possible explanation of this condition to occur was that the hammer tests were performed on the top side of concrete plate. As discussed earlier in the section, it was found that, during the service life of CWICS, a $20 \mathrm{~mm}$ non-shrinking grouting material was laid on top of the concrete plate. This material does not contain any coarse aggregate and therefore leads to lower rebound number of hammer tests. Hammer test performed on the other elements such as beam and wall elements gave a higher rebound number than that obtained from concrete plate element. However, no concrete drill samples were taken from beam and wall elements as field condition did not allow the drilling process to be executed on these elements.

Concrete porosity is the major factor that influences both strength and durability of concrete structure. Concrete with 


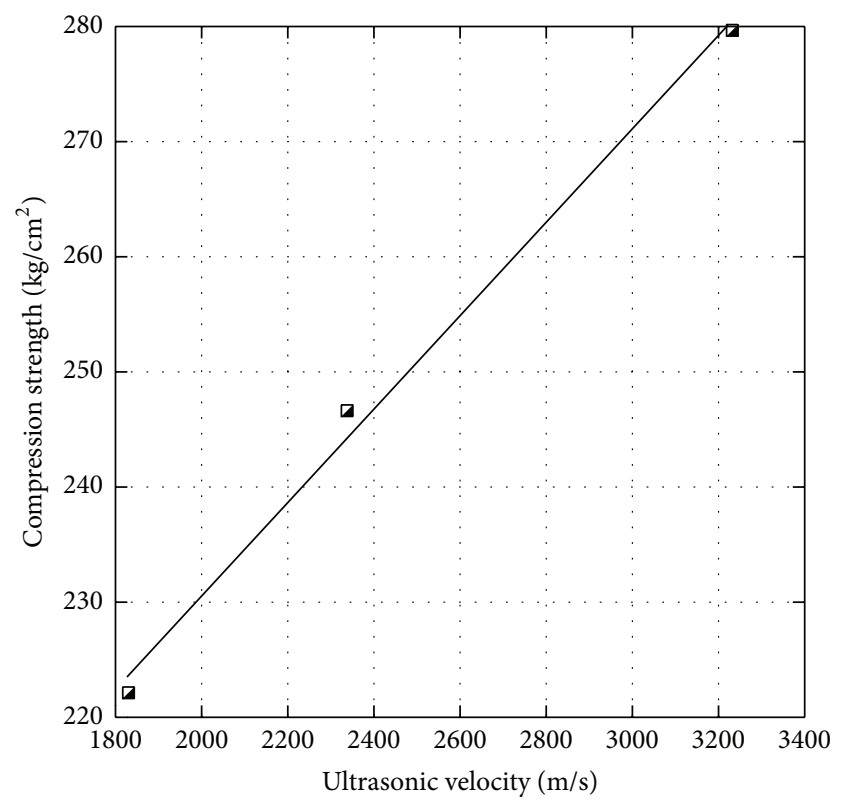

$y=149.41+0.040568 \times R=0.99739$

FIGURE 9: Correlation between UPV and compression strength for train $\mathrm{A} / \mathrm{B}$.

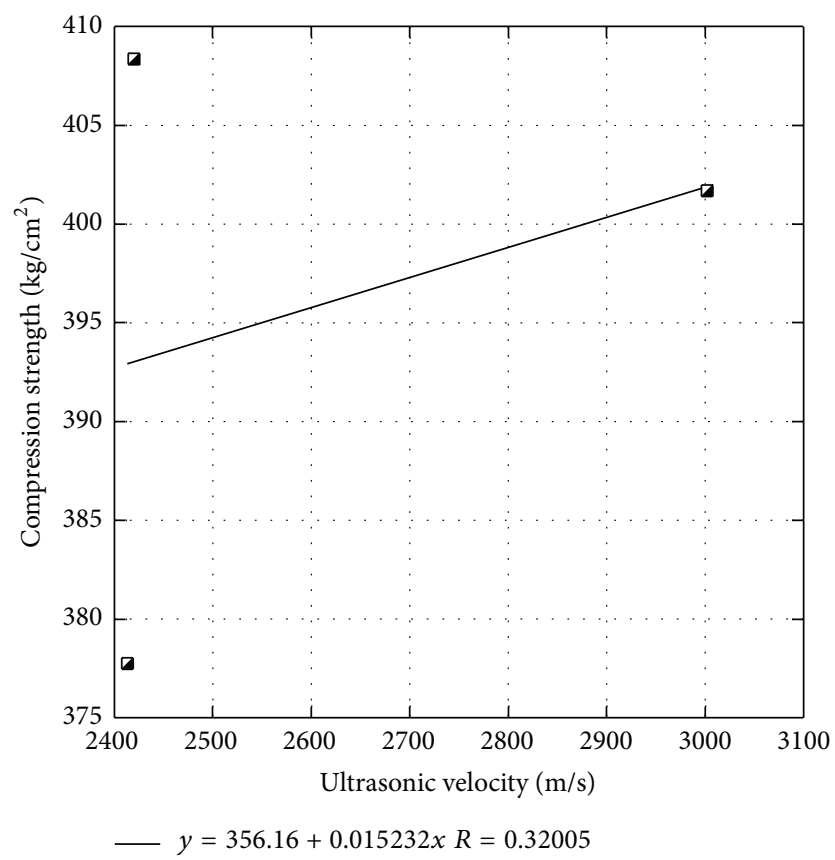

FIGURE 10: Correlation between UPV and compression strength for train $\mathrm{C} / \mathrm{D}$.

high porosity has a low concrete strength and low durability. A number of methods can be used to determine the porosity of concrete such as saturation method, helium pycnometry and mercury intrusion porosimetry. For this study, porosity test was performed using vacuum saturation apparatus [9]. The result of this test is presented in Table 4. This table shows that most of the sample has a porosity less than $10 \%$, except

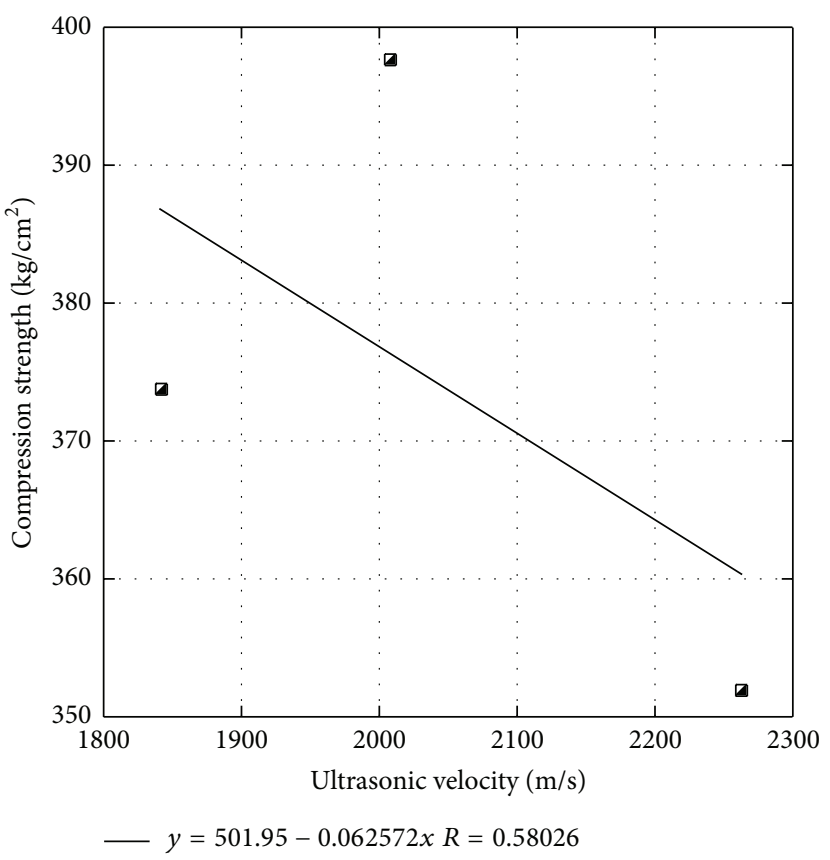

FIGURE 11: Correlation between UPV and compression strength for train $\mathrm{E} / \mathrm{F}$.

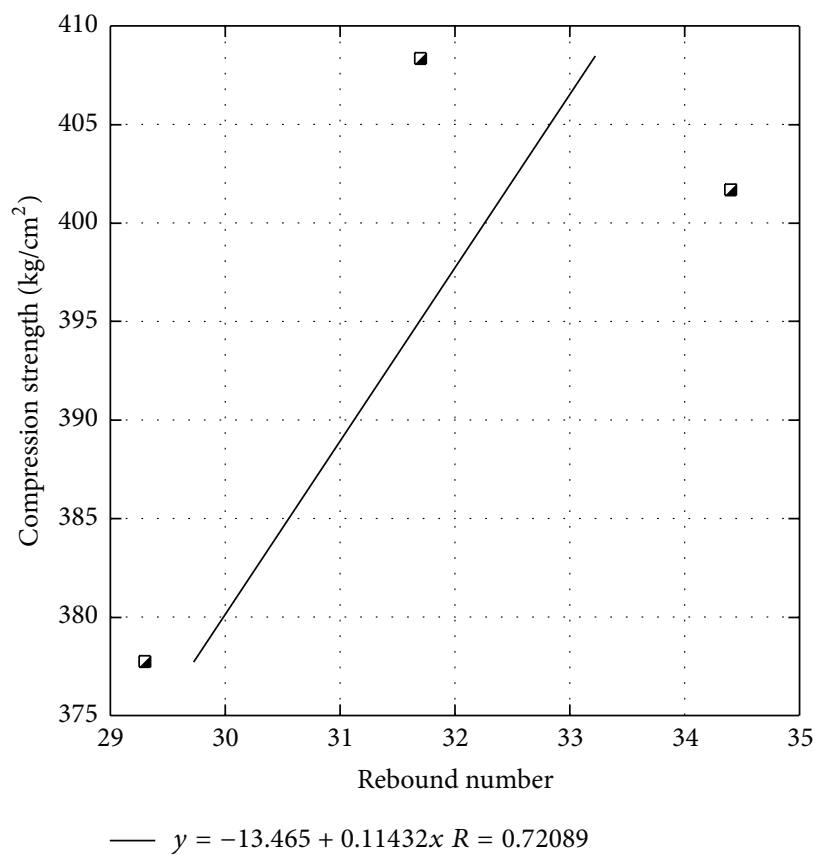

FIGURE 12: Correlation between hammer and compression strength for train $\mathrm{C} / \mathrm{D}$.

for the sample taken from core 1 . Core 1 has the highest porosity of $11.5 \%$. This value also corresponds with its lowest compressive strength of all samples. By comparison, core 6 has the lowest porosity at $4.3 \%$, but it gives only the second highest value of all compressive strength.

Compared with the available data in the literature [10, 11 ], the porosity of concrete given in Table 4 is lower for 


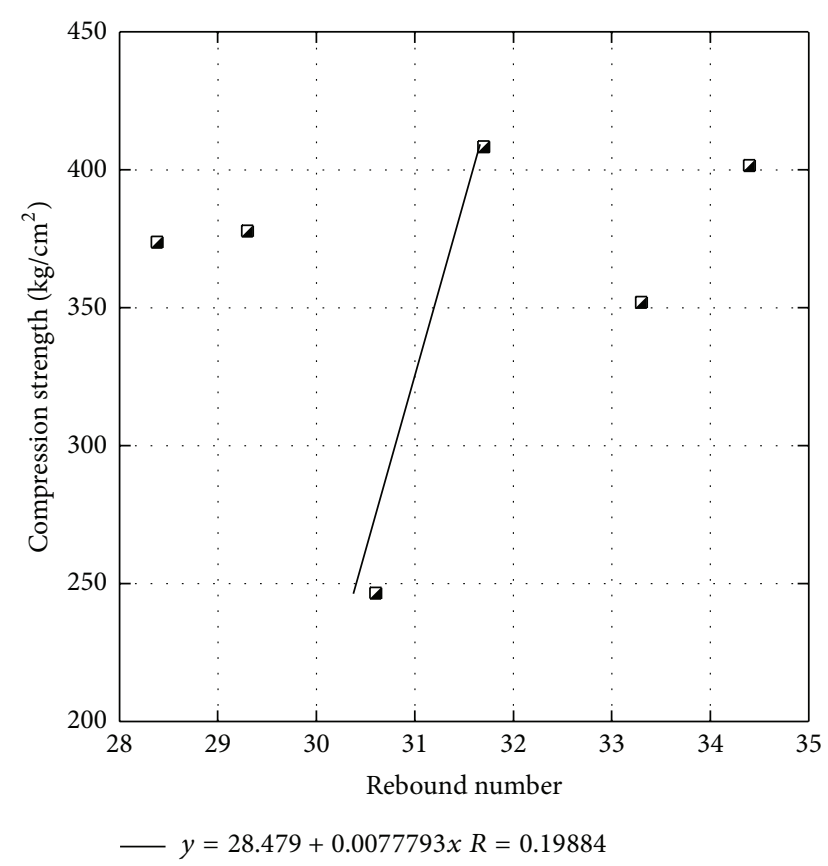

FIGURE 13: Correlation between hammer and compression strength for all trains.

TABLE 4: Porosity test of concrete core-drilled samples.

\begin{tabular}{lccc}
\hline Code & Train & Porosity & $\begin{array}{c}\text { Compressive strength } \\
\left(\mathrm{kg} / \mathrm{cm}^{2}\right)\end{array}$ \\
\hline Core 1 & A/B & $11.5 \%$ & 222.13 \\
Core 2 & A/B & $7.8 \%$ & 246.63 \\
Core 6 & C/D & $4.3 \%$ & 408.35 \\
Core 9 & C/D & $9.8 \%$ & 377.76 \\
Core 10 & E/F & $8.3 \%$ & 373.76 \\
Core 14 & G/H & $8.4 \%$ & 411.01 \\
\hline
\end{tabular}

the same concrete strength. The data in the literature shows that for concrete strength of 30 to $40 \mathrm{MPa}$, the porosity of concrete is found around 15 to $20 \%$. On the contrary, data in Table 4 shows concrete porosity of $4.3-11.5 \%$ but with corresponding max concrete strength of only $40 \mathrm{MPa}$. It must be mentioned herein that all the available data in the literatures was mostly taken at 28-90 days old, while porosity data presented herein was taken after 19-33 years old. It appears that older concrete gives lower porosity than younger concrete but without significant strength gains.

Figure 14 shows the correlation chart between porosity and compressive strength for all trains. Compared with Figure 13, porosity has a better correlation to compressive strength than hammer test, having a correlation factor of 0.54 . This result again confirms that destructive test such as porosity test has a better accuracy than nondestructive test such as UPV test. However, porosity test requires the samples to be taken from an existing structure and therefore it is expensive to perform.

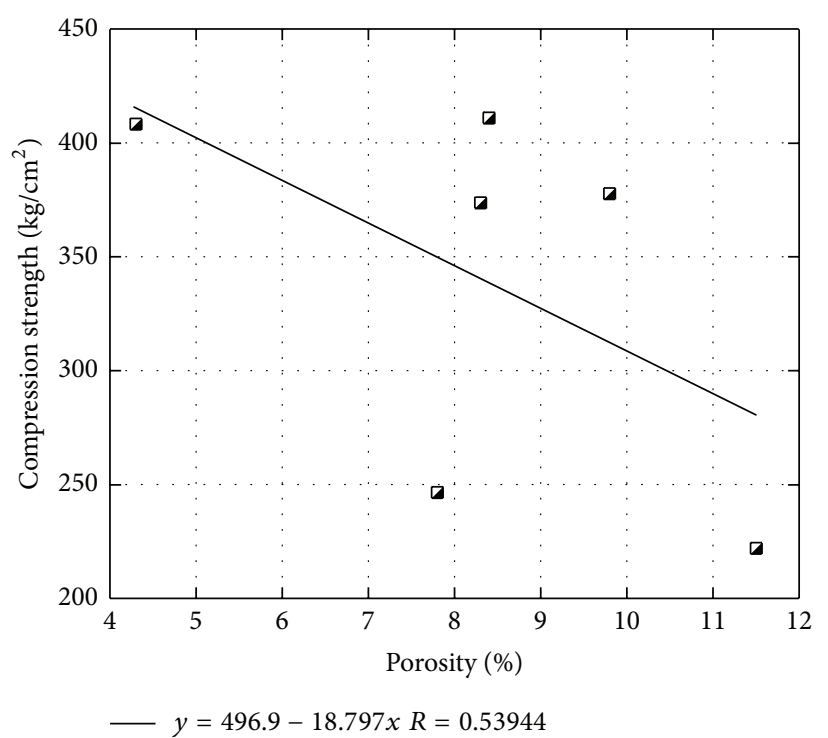

FIGURE 14: Correlation between porosity and compression strength for all trains.

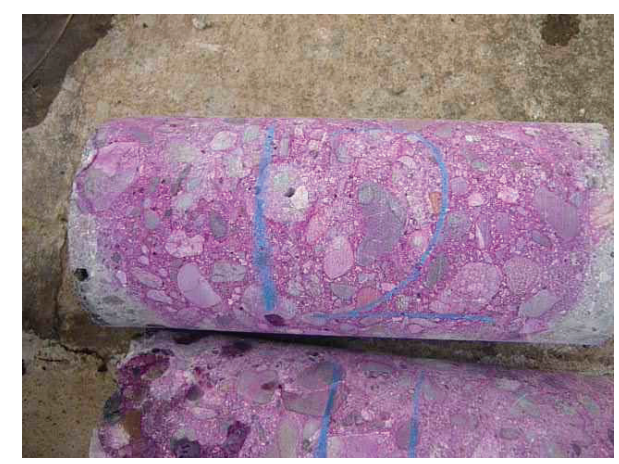

Figure 15: Carbonation test of core-drilled samples.

4.2. Determine Carbonation Depth. After concrete coredrilled sample was obtained, the cylinder specimen was then straight away tested for depth of carbonation. Depth of carbonation was checked using a solution of phenolphthalein indicator that appears pink in contact with alkaline concrete with $\mathrm{pH}$ values in excess of 9 and colourless at lower levels of $\mathrm{pH}$ [12]. This test is most commonly performed by spraying the indicator on freshly exposed surfaces of concrete broken from the structure or on split cores. All of the fourteen samples changed their color to pink as shown in Figure 15. This showed that no concrete carbonation was detected for CWICS up to the present, despite the fact that some of the trains have been in service for more than 30 years.

4.3. Determine Yields Strength of Rebar and Remaining Steel Rebar Thickness. Yield strength of rebar can be obtained from available as-built drawing. However, to get a more accurate data of yield strength, tensile test was performed. Reinforcing bars extracted during concrete core-drilled were used as specimen samples. Four samples of rebar were successfully 
TABLE 5: Corrosion thickness of rebar.

\begin{tabular}{lcccccc}
\hline Number & Code & Rebar diameter & Train & Corrosion thickness & Corrosion rate (mm/year) & Microstructure \\
\hline 1 & Core 3 & D 19 & A/B & $10 \sim 20 \mu \mathrm{m}$ & $0.0003-0.0006$ & Pearlite and Ferrite \\
2 & Core 8 & $D 19$ & C/D & $20 \sim 50 \mu \mathrm{m}$ & $0.0007-0.0017$ & Pearlite and Ferrite \\
3 & Core 15 & $D 19$ & G/H & $3 \sim 8 \mathrm{~mm}$ & $0.1875-0.5$ & Pearlite and Ferrite \\
\hline
\end{tabular}

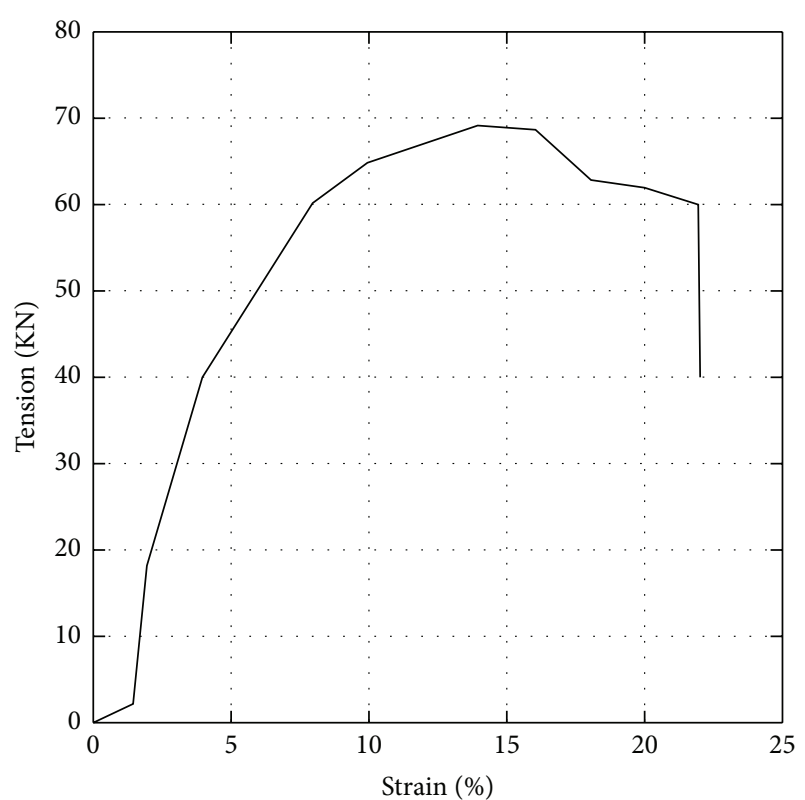

FIGURE 16: Force and displacement of rebar from tension test.

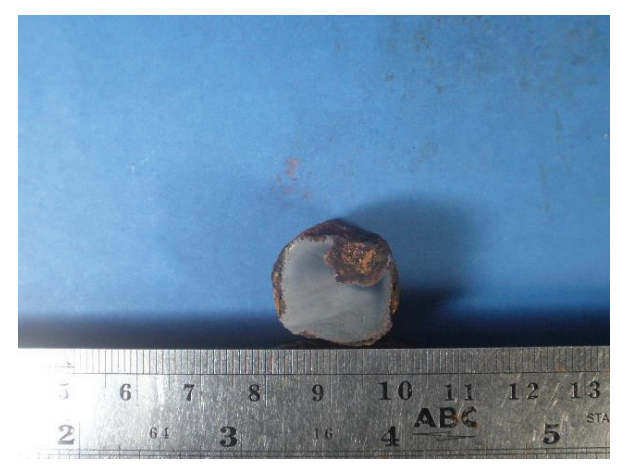

FIGURE 17: Corrosion thickness of $3 \sim 8 \mathrm{~mm}$ taken from core 15 .

tensile tested. The result of one of tensile test is shown in Figure 16. The yield strength of rebar was found between 533 and $560 \mathrm{MPa}$, whereas their corresponding ultimate strengths were found between 759 and $878 \mathrm{MPa}$. This yield strength was higher than that of the specified yield strength of $400 \mathrm{MPa}$.

The loss of rebar thickness due to corrosion was measured using Olympus metallurgical camera and Union metallurgical microscope, as shown in Figures 17 and 18. The rebar samples for this test were obtained from concrete coredrilled. Table 5 shows the corrosion thickness of the rebar for each train. This table shows that train $\mathrm{E} / \mathrm{F}$ has the highest

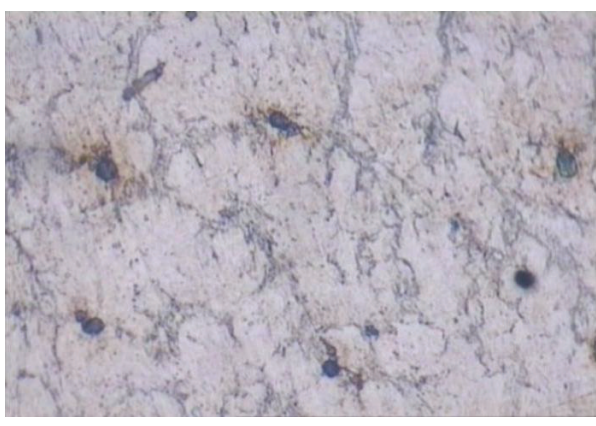

FIGURE 18: Microstructure with 500x magnification of rebar taken from core 15.

corrosion rates of $0.1875-0.5 \mathrm{~mm} /$ year. This corrosion rate is much higher than the corrosion rate of trains $\mathrm{A} / \mathrm{B}$ and $\mathrm{C} / \mathrm{D}$ at $0.0003-0.0006$ and $0.0007-0.0017 \mathrm{~mm} /$ year, respectively. These two trains have almost negligible corrosion. The higher corrosion rate observed at train $\mathrm{E} / \mathrm{F}$ is most likely due to local incidence such as local low concrete compaction. Therefore, this value should not be used as a representative value of the steel corrosion rate of train E/F. Furthermore, as only one sample was taken for this test for each train, this result should be used cautiously and should be compared with other forms of tests or formulae to determine the corrosion rate of CWICS. The representative value of corrosion rate of each train will be discussed and determined in Section 4.8.

\subsection{Determine Depth and Chloride Content and Concrete} $\mathrm{pH}$ in the Concrete. After compression test of core-drilled sample, the debris from this test was chloride tested. Three different depths were used to measure the chloride content, that is, $0.0,2.5$, and $5.0 \mathrm{~cm}$ from concrete surface. At the same time, the $\mathrm{pH}$ of the concrete was also measured. The results of chloride test and $\mathrm{pH}$ test are presented in Figures 19 and 20, respectively.

Figure 19 shows that the chloride content measured by weight of concrete (in \%) at concrete surface for all samples is very close to one another, except sample taken from core 15. Core 15 drilled at train $\mathrm{G} / \mathrm{H}$ shows the highest chloride content at all measured depths. This highest chloride content correlates with its highest thickness loss of rebar as presented in Table 5. Figure 19 also indicates that all of the samples have a very similar chloride content of $0.01 \%$ at concrete depth of $50 \mathrm{~mm}$, where the rebar is located. This value can be compared with the chloride threshold level to initiate corrosion of $0.025 \%$ such as stipulates in Indonesia Concrete Building Code [2].

Figure 20 shows that the concrete $\mathrm{pH}$ is relatively constant as the depth from concrete surface increases. The lowest $\mathrm{pH}$ is 


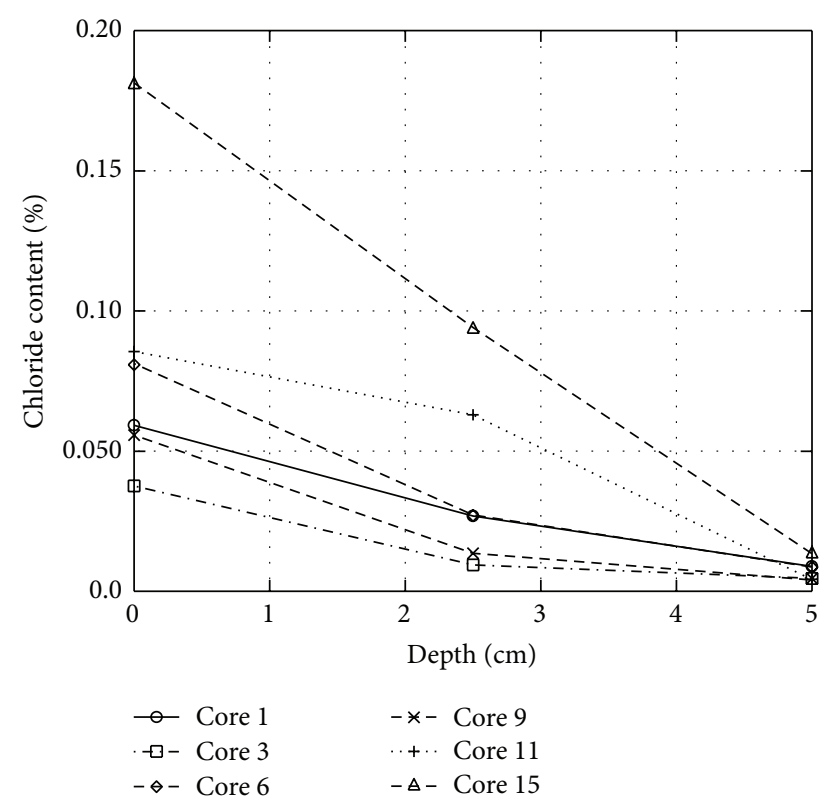

FIGURE 19: Chloride content at different depths.

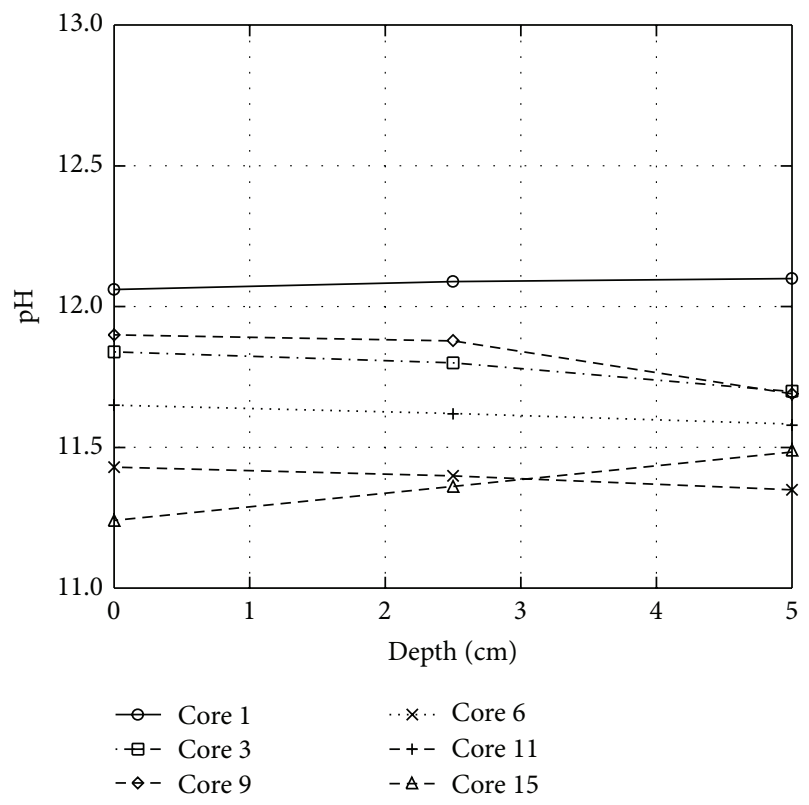

Figure 20: pH value at different concrete depth.

11.25 at concrete surface and 11.35 at $5 \mathrm{~cm}$ depth. This indicates that the concrete is still in a very high alkaline condition and has no experience $\mathrm{pH}$ reduction due to corrosion attack. This result corroborates with previous result (see Figure 19) which indicate that concrete corrosion has not yet initiated at CWICS. Note that core 15 which has the highest chloride content also has the lowest $\mathrm{pH}$ at concrete depth of 0.0 and $25 \mathrm{~mm}$ and the second lowest $\mathrm{pH}$ at concrete depth of $50 \mathrm{~mm}$. Core 15 also has the highest thickness loss of rebar as shown in Table 5.
TABLE 6: Main aggressive element in sea water.

\begin{tabular}{lccc}
\hline Parameter & Unit & \multicolumn{3}{c}{ Sample } \\
& & 1 & 2 \\
\hline $\mathrm{pH}$ & & 7.77 & 7.82 \\
Sulphate & $\mathrm{mg} / \mathrm{L}$ & 1600 & 1585 \\
\hline Chloride & $\mathrm{mg} / \mathrm{L}$ & 14250 & 14240 \\
\hline
\end{tabular}

4.5. Determine Chloride and Sulphate Content of Sea Water. Sea water surrounding CWICS was tested to determine the concentration of its main aggressive elements that influence the degree of chloride attack. Two samples were tested and the results are presented in Table 6. This table shows that the highest chloride and sulphate content of the sea water is $14250 \mathrm{mg} / \mathrm{L}$ and $1600 \mathrm{mg} / \mathrm{L}$, respectively. These values are lower than the chloride and sulphate content of sea water found in the Persian Gulf [13] at $26800 \mathrm{mg} / \mathrm{L}$ and $3460 \mathrm{mg} / \mathrm{L}$, respectively. These lower contents are possibly caused by high water rainfall in Indonesia than that in the Persian Gulf.

4.6. Determine the Probability of Corrosion of Rebar. The risk of corrosion of rebar in concrete can be estimated using half-cell potential test. Half-cell potential test is simple, cheap, and nondestructive. The electrode used for this test is copper/copper sulphate electrode (CSE). The test was performed based on ASTM [14]. The result of this test is summarized in Table 7.

Table 7 shows that the most negative potential of rebar (i.e., $-0.520 \mathrm{mV}$ ) was found at train $\mathrm{C} / \mathrm{D}$, followed by trains $\mathrm{A} / \mathrm{B}, \mathrm{E} / \mathrm{F}$, and $\mathrm{G} / \mathrm{H}$. All potential readings indicate that the potential of rebar is already in negative side. According to ASTM C-876, the potential reading less than $-350 \mathrm{mV}$ means that the probability of corrosion of rebar is greater than $90 \%$. If the result of potential measurement is combined with $\mathrm{pH}$ test (i.e., $-0.520 \mathrm{mV}$ and $\mathrm{pH} 11.35$ ) and then plotted using Pourbaix diagram, then the corrosion tendency of rebar can be seen in Figure 21. This figure shows that the concrete of CWICS is still in noncorroding stage (at passivation zone). This result confirms the result of corrosion rate measurement discussed in Section 4.3 which indicates that the train has almost negligible corrosion rate as found in cores 3 and 8 . However, this condition may turn in to corroding stage if the concrete $\mathrm{pH}$ decreases to less than 10.0.

4.7. Structural and Load Modelling of CWICS. Structural and load modeling of CWICS was performed using SAP 2000 to determine the internal forces of CWICS. These internal forces were then compared with the remaining capacity of CWICS's structural elements. The remaining capacity of CWICS has decreased from its initial design capacity due to rebar corrosion. If ratio of the capacity of concrete element to the internal force of the element (defined herein as safety factor) is greater than unity, the element is considered in a safe condition. However, if this ratio reaches unity or less, the element theoretically has failed and has to be strengthened to achieve the minimum safety of 1.0. Note that the redundancy effect of this highly indeterminate structure 


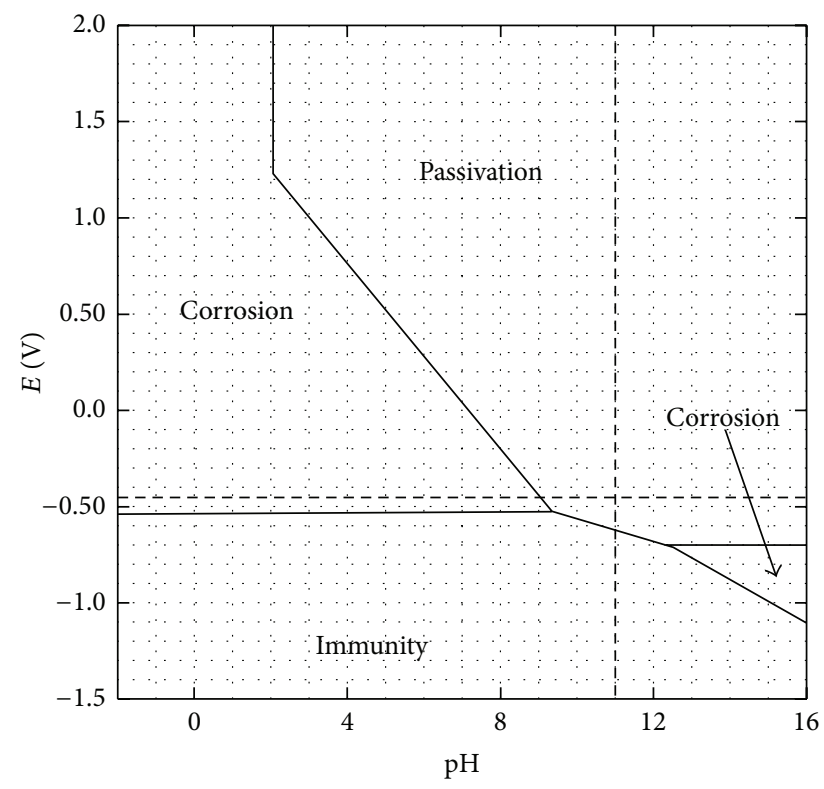

FIgURE 21: Pourbaix diagram of rebar.

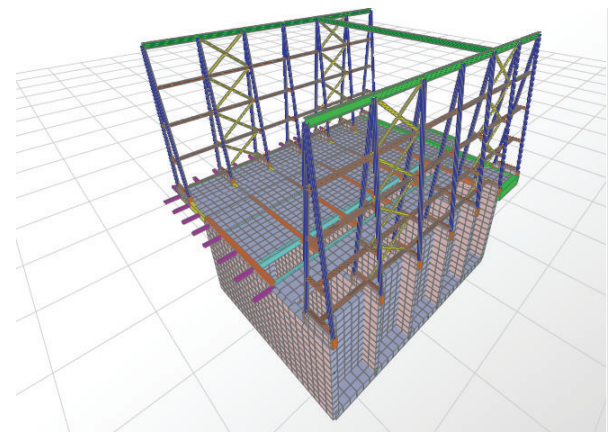

Figure 22: Structural model of train A/B.

was not considered in this analysis when safety factor of element was determined. Therefore, it must be mentioned here that the actual safety factor of CWICS may be higher than the calculated safety factor obtained from this analysis.

Figure 22 shows structural model of CWICS of train A/B. The structure comprises beam, plate (slab), and wall elements. Loads considered in this analysis were dead, live, equipment, and earthquake load. To get the maximum internal forces in the concrete element, different load combination is determined based on Indonesia Concrete Code [2]. The distribution of bending moment of train $\mathrm{A} / \mathrm{B}$ due to dead and live is shown in Figure 23.

4.8. Determine Rate of Deterioration. Rate of concrete deterioration or corrosion rate can be determined by two following methods. These are

(i) direct method;

(ii) indirect method.

Direct method of corrosion rate estimation can be performed by measuring either weight loss or thickness loss of

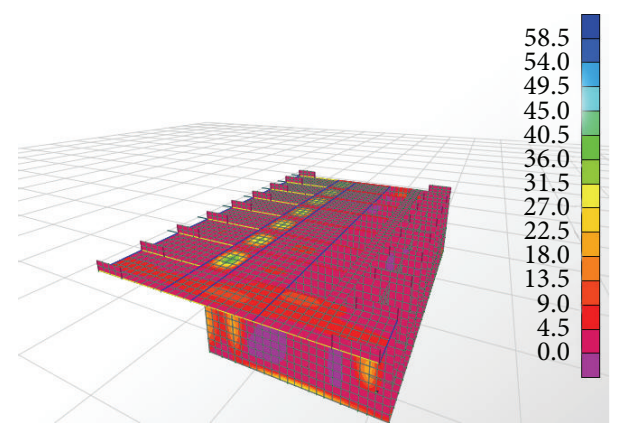

FIGURE 23: Bending moment distribution of train A/B.

TABLE 7: Half-cell potential measurement of rebar.

\begin{tabular}{|c|c|c|c|c|}
\hline Number & Train A/B & $\begin{array}{r}\text { Train C/D } \\
\text { Readin }\end{array}$ & $\begin{array}{l}\text { Train E/F } \\
\text { (mV) }\end{array}$ & Train G/H \\
\hline 1 & -0.380 & -0.120 & -0.080 & -0.090 \\
\hline 2 & -0.330 & -0.130 & -0.090 & -0.070 \\
\hline 3 & -0.220 & -0.090 & -0.120 & -0.100 \\
\hline 4 & -0.370 & -0.030 & -0.100 & -0.070 \\
\hline 5 & -0.180 & -0.120 & -0.110 & -0.080 \\
\hline 6 & -0.220 & -0.090 & -0.130 & -0.100 \\
\hline 7 & -0.120 & -0.130 & -0.150 & -0.120 \\
\hline 8 & -0.130 & -0.280 & -0.130 & -0.060 \\
\hline 9 & -0.180 & -0.140 & -0.100 & -0.080 \\
\hline 10 & -0.200 & -0.140 & & \\
\hline 11 & -0.220 & -0.160 & & \\
\hline 12 & -0.150 & -0.120 & & \\
\hline 13 & -0.180 & -0.240 & & \\
\hline 14 & -0.210 & -0.190 & & \\
\hline 15 & -0.140 & -0.180 & & \\
\hline 16 & -0.050 & -0.200 & & \\
\hline 17 & -0.050 & -0.270 & & \\
\hline 18 & -0.050 & -0.320 & & \\
\hline 19 & -0.050 & -0.270 & & \\
\hline 20 & -0.100 & -0.270 & & \\
\hline 21 & & -0.270 & & \\
\hline 22 & & -0.340 & & \\
\hline 23 & & -0.510 & & \\
\hline 24 & & -0.520 & & \\
\hline 25 & & -0.520 & & \\
\hline Minimum & -0.380 & -0.520 & -0.150 & -0.120 \\
\hline Maximum & -0.050 & -0.030 & -0.080 & -0.060 \\
\hline Average & -0.177 & -0.226 & -0.112 & -0.086 \\
\hline
\end{tabular}

rebar. This method requires the steel sample to be extracted from existing structure. Table 5 shows the result of direct method of corrosion rate measurement of CWICS. This table shows that trains $\mathrm{A} / \mathrm{B}$ and $\mathrm{C} / \mathrm{D}$ have much lower corrosion rate than the newer train $\mathrm{G} / \mathrm{H}$. In this case, this methods yield a contradictory results with actual field condition of CWICS, which shows that older train shows more sign of distress than newer train. For this reason, indirect method of 
TABLE 8: Concrete cover thickness.

\begin{tabular}{lcc}
\hline \multirow{2}{*}{ Location } & \multicolumn{2}{c}{ Concrete cover $(\mathrm{mm})$} \\
& Min & Average \\
\hline Train A/B & 50.0 & 83.3 \\
Train C/D & 32.5 & 65.0 \\
Train E/F & 53.0 & 74.0 \\
Train G/H & 44.0 & 61.7 \\
\hline
\end{tabular}

corrosion rate measurement was employed in this study and direct method was mainly used for comparison purpose only.

Indirect method of corrosion rate estimation was performed by using empirical formulae available in many literatures. These formulae were developed through three decades of research on corrosion mechanism and will be discussed briefly in the following paragraph. To estimate concrete rate of deterioration using indirect method, the actual concrete cover needs to be measured. The thickness of concrete cover determines the resistant of concrete structure against corrosive agent such as chloride. To initiate corrosion, chloride must penetrate concrete cover, reach the rebar level, and accumulate to chloride threshold level. In this study, concrete cover was measured using Profometer $5+$. The result of this test is summarized in Table 8 . Note that based on the available document, the specified concrete cover was $75 \mathrm{~mm}$.

Table 8 shows that the lowest average concrete cover is $61.7 \mathrm{~mm}$ found in train $\mathrm{G} / \mathrm{H}$. This value can be compared with the minimum cover thickness as specified in Indonesian Concrete Standard [2], which stipulates that the minimum cover for corrosive environment is $65 \mathrm{~mm}$. However, all the minimum cover found during the test does not comply with the present day code requirement. The actual concrete cover found during this test can be also used as indication of quality control during construction phase. It is very surprising that the oldest train (train A/B) shows a better quality in terms of cover thickness than the newer trains. Train A/B has the highest average concrete cover and the highest minimum concrete cover at $83.3 \mathrm{~mm}$ and $50.0 \mathrm{~mm}$, respectively.

Deterioration stage of reinforced concrete structure subjected to corrosion can be divided in two stages [15]:

(i) corrosion initiation;

(ii) corrosion propagation.

The time required for the chloride concentration at the steel surface to reach the threshold chloride concentration needed to destroy the passive layer of the steel is defined as corrosion initiation. The second stage is called corrosion propagation, where steel reinforcing bar corrodes causing loss of area (metal loss) and reduces flexural and shear strength.

Corrosion initiation can be determined using Fick's second law [16] as

$$
T_{i}\left(C_{o}, C_{\mathrm{th}}, D, d_{c}\right)=\frac{d_{c}^{2}}{4 D\left[\operatorname{erf}^{-1}\left(1-\left(C_{\mathrm{th}} / C_{o}\right)\right)\right]^{2}},
$$

where $C_{o}=$ chloride content at concrete surface, $C_{\text {th }}=$ threshold chloride content to initiate corrosion, $D=$ concrete diffusion coefficient, $d_{c}=$ concrete cover, and erf $=$ the error function.

Chloride content at concrete surface $\left(C_{o}\right)$ has been determined from chloride test discussed at Section 4.4, while threshold chloride content to initiate corrosion $\left(C_{\mathrm{th}}\right)$ is prescribed in most concrete codes or used empirical values found in the literature. The average and minimum value of concrete cover shown in Table 8 can be used in corrosion initiation calculation to obtain two scenarios of deterioration, that is, average and worst case scenarios.

The concrete diffusion coefficient in (1) can be estimated using empirical formulae [17] as

$$
\begin{aligned}
& D=10^{-10+(4.66 \mathrm{w} / \mathrm{c})}, \\
& \frac{\mathrm{w}}{\mathrm{c}}=\frac{27}{f_{\mathrm{cyl}}^{\prime}+13.5},
\end{aligned}
$$

where $\mathrm{w} / \mathrm{c}$ is the water cement ratio and $f_{\text {cyl }}^{\prime}$ is the cylinder compressive strength from core-drilled concrete.

Corrosion propagation is determined using empirical formula [15] as

$$
i_{\text {corr }}=\frac{27.0(1-\mathrm{w} / \mathrm{c})^{-1.64}}{d_{c}}\left(\mu \mathrm{A} / \mathrm{cm}^{2}\right)
$$

where $i_{\text {corr }}$ is corrosion rate in $\mu \mathrm{A} / \mathrm{cm}^{2}$. Note that a corrosion current density of $1 \mu \mathrm{A} / \mathrm{cm}^{2}$ is equal to a steel section loss of $11.6 \mu \mathrm{m} /$ year [18].

The above formulae is used to predict the corrosion rates in concrete structures for mean relative humidity $(\mathrm{RH})$ of $80 \%$ and mean temperature of $20^{\circ} \mathrm{C}$. To obtain corrosion rate at different temperature, the following formulae [5] can be utilized:

$$
i_{\text {corr }}(t)=i_{\text {corr- } 20}[1+0.073 \times(t-20)]
$$

where $i_{\text {corr }}(t)=$ corrosion rate temperature $>20^{\circ} \mathrm{C}, i_{\text {corr- } 20}=$ corrosion rate temperature $20^{\circ} \mathrm{C}$, and $t=$ temperature $\left({ }^{\circ} \mathrm{C}\right)$.

At the present study, the average temperature used was $31^{\circ} \mathrm{C}$. Using this value and (4), the corrosion rate increases around $80 \%$ compared with corrosion rate at $20^{\circ} \mathrm{C}$.

Assuming general uniform corrosion, as displayed in Figure 24, the diameter reduction of reinforcing bar (rebar) due to corrosion can be estimated as

$$
\Delta D\left(T_{o}\right)=0.0232 \times i_{\text {corr }} \times T_{o} .
$$

The remaining area of rebar can then be determined as

$$
A_{s}\left(T_{o}\right)=\frac{\pi}{4}\left(D_{o}-0.0232 \times i_{\mathrm{corr}} T_{o}\right)^{2}
$$

where $T_{o}$ is time measured after corrosion initiation.

Using (1) to (6), concrete deterioration then can be determined. Two scenarios were used for this study:

(a) worst case condition scenario;

(b) average case condition scenario. 
TABLE 9: Corrosion initiation time and concrete deterioration rate.

\begin{tabular}{|c|c|c|c|c|c|c|c|c|}
\hline Train & \multicolumn{2}{|c|}{$\mathrm{A} / \mathrm{B}$} & \multicolumn{2}{|c|}{$\mathrm{C} / \mathrm{D}$} & \multicolumn{2}{|c|}{$\mathrm{E} / \mathrm{F}$} & \multicolumn{2}{|c|}{$\mathrm{G} / \mathrm{H}$} \\
\hline Scenarios & Worst case & Average case & Worst case & Average case & Worst case & Average case & Worst cas & Average case \\
\hline Built (year) & \multicolumn{2}{|c|}{1977} & \multicolumn{2}{|c|}{1982} & \multicolumn{2}{|c|}{1987} & \multicolumn{2}{|c|}{1995} \\
\hline Operated (year) & \multicolumn{2}{|c|}{1979} & \multicolumn{2}{|c|}{1984} & \multicolumn{2}{|c|}{1989} & \multicolumn{2}{|c|}{1997} \\
\hline Compressive strength $f^{\prime} c(\mathrm{MPa})$ & 22.2 & 24.9 & 37.8 & 39.6 & 35.1 & 37.4 & 41.1 & 41.1 \\
\hline Cover thickness (mm) & 50 & 83 & 32.5 & 65 & 53 & 74 & 44 & 61.7 \\
\hline Corrosion initiation (year) & 1.82 & 13.91 & 5.73 & 35.56 & 10.25 & 26.13 & 6.99 & 26.13 \\
\hline Corrosion rate (mm/year) & 0.229 & 0.100 & 0.118 & 0.056 & 0.081 & 0.053 & 0.079 & 0.056 \\
\hline Remaining capacity at 2013 (\%) & $44 \%$ & $83 \%$ & $77 \%$ & $100 \%$ & $90 \%$ & $100 \%$ & $94 \%$ & $100 \%$ \\
\hline Remaining capacity in 20 year (\%) & $21 \%$ & $67 \%$ & $59 \%$ & $93 \%$ & $77 \%$ & $92 \%$ & $80 \%$ & $92 \%$ \\
\hline
\end{tabular}

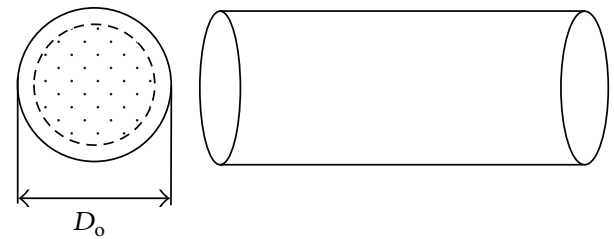

FIGURE 24: General uniform corrosion.

In the worst case scenario, all parameters used in the analysis were either the minimum or the maximum value obtained from the test in order to get the fastest deterioration of structure. For example, the minimum value was used for concrete cover thickness and concrete strength parameter, whereas the maximum value was used for chloride content parameter. By contrast, average values of parameters were used for the average case scenario. Table 9 summarizes the results of analysis using these two scenarios. Note that concrete strength used in this analysis is concrete strength obtained from compressive test of concrete core-drilled samples.

Table 9 shows that train A/B has the shortest corrosion initiation time for the worst and average scenarios as it has the lowest compressive strength. This train also has the highest corrosion rate at around $0.229 \mathrm{~mm}$ /year for worst case scenario and $0.1 \mathrm{~mm} /$ year for average case scenario, respectively. It is interesting to compare these corrosion rates with corrosion rates obtained using direct method as shown in Table 5. The corrosion rate of train $\mathrm{A} / \mathrm{B}$ using indirect method for the two scenarios is higher than that obtained from direct method, which gives corrosion rate of 0.0003$0.0006 \mathrm{~mm} /$ year. Therefore, corrosion rate based on indirect method yields more conservative results than that from direct method. For this reason, the corrosion rate from indirect method will be used for determining the remaining capacity of CWICS.

Based on the above assumption, for the worst case scenario, the remaining capacity of train $\mathrm{A} / \mathrm{B}$ at 2013 is $44 \%$ of the initial capacity. However, for the average condition scenario, the- 2013 capacity of train A/B is around $83 \%$ of the initial capacity. This average condition appears to better represent the actual train condition as up to now this train is still in service and there is no indication of significant of distress of the train.

Table 9 also indicates that, for average case scenario, the remaining capacity of train C/D, E/F, and G/H at year 2013 is still $100 \%$ of their initial design capacities. By year 2033, these remaining capacities have decreased to $93 \%, 92 \%$, and $92 \%$, respectively. By comparison, for worst case scenario the remaining capacity of these trains at year 2013 are $77 \%$, 90\%, and $94 \%$ of their initial design capacities, respectively. By year 2033 , these remaining capacities reduce to $59 \%, 77 \%$, and $80 \%$ of their initial design capacity, respectively.

4.9. Determine Safety Factor. To better capture the current condition of CWICS, the reduction of safety factor of different element of CWICS due to rebar corrosion against flexure and shear action will be presented. Only the result of analysis of train $\mathrm{A} / \mathrm{B}$ will be discussed in the next section as this train has the worst condition.

The safety factor of concrete element against flexure and shear can be formulated as

$$
\begin{gathered}
\mathrm{SF}=\frac{\varphi M_{n}\left(T_{o}\right)}{M_{u}}>1.0, \\
\mathrm{SF}=\frac{\varphi V_{n}\left(T_{o}\right)}{V_{u}}>1.0,
\end{gathered}
$$

where $M_{n}\left(T_{o}\right)=$ nominal flexural capacity of concrete element at $T_{o}$ after corrosion has initiated, $M_{u}=$ flexural moment due to factor load obtained from structural analysis, $V_{n}\left(T_{o}\right)=$ nominal shear capacity of concrete element at $T_{o}$ after corrosion has initiated, and $V_{u}=$ shear due to factor load obtained from structural analysis.

The capacity of concrete element against flexure and shear at $T_{o}$ can be determined as

$$
\begin{gathered}
M_{n}\left(T_{o}\right)=A_{s}\left(T_{o}\right) \times f_{y} \times 0.8 \times d, \\
V_{n}\left(T_{o}\right)=\frac{1}{6} \sqrt{f_{c}^{\prime}} \times b_{w} \times d+\frac{A_{v}\left(T_{o}\right) \times f_{y} \times d}{s},
\end{gathered}
$$

where $A_{s}\left(T_{o}\right)=$ area of rebar section at time $T_{o}, f_{y}=$ yield strength of rebar, $h=$ height of section, $f_{c}^{\prime}=$ concrete compressive strength, $b_{w}=$ width of section, $d=$ effective 


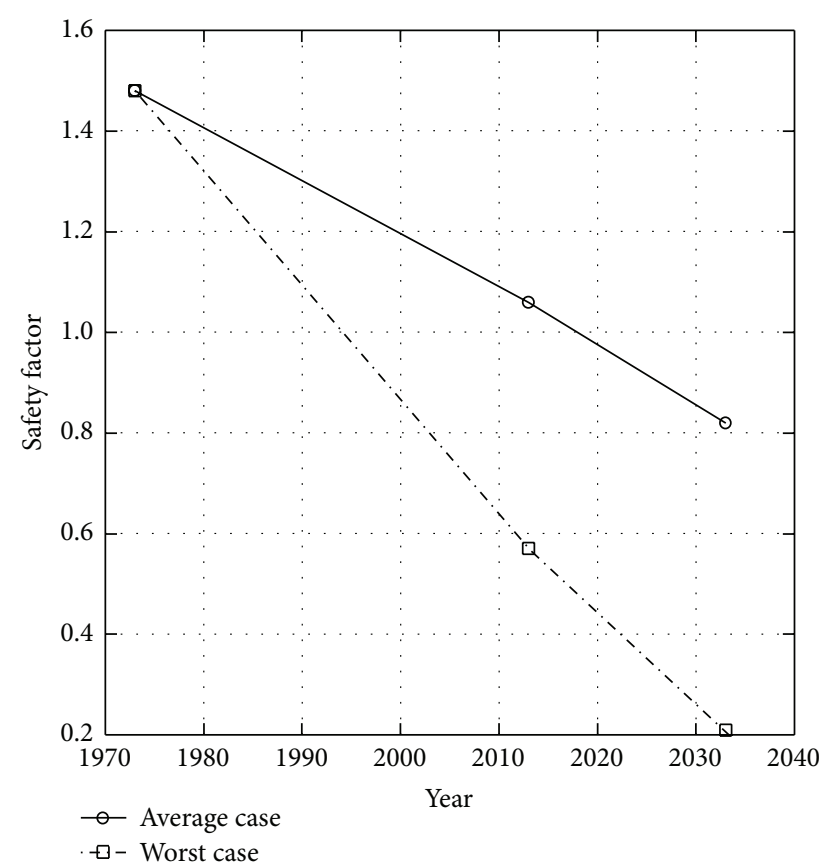

FIGURE 25: Safety factor for plate element with $600 \mathrm{~mm}$ depth and reinforced with $19 \mathrm{~mm}$ diameter rebar at $150 \mathrm{~mm}$ spacing.

depth of section, $A_{v}\left(T_{o}\right)=$ area of shear reinforcement at time $T_{o}$, and $s=$ spacing of shear reinforcement.

The area of rebar for flexure defined as $A_{s}\left(T_{o}\right)$ and for shear defined as $A_{v}\left(T_{o}\right)$ can then be determined using (6). For the purpose of this study, the safety was determined at year 2013 and year 2033 using (7) to (10). Figure 25 shows the reduction of safety factor for concrete plate element with $600 \mathrm{~mm}$ depth and reinforced with $19 \mathrm{~mm}$ rebar diameter at $150 \mathrm{~mm}$ spacing.

Figure 25 indicates that, for average case scenarios, the safety factor of $600 \mathrm{~mm}$ plate element decreases from 1.48 to 1.06 at year 2013 and to 0.82 at year 2033, respectively. By comparison, for worst case scenarios, the safety factor decreases from 1.48 to 0.57 at year 2013 and to 0.21 at year 2033 , respectively. Therefore, this element requires immediate strengthening as the safety factor already approaches 1.0 at year 2013.

Figure 26 shows the reduction of safety factor for concrete wall element with $600 \mathrm{~mm}$ depth and reinforced with $22 \mathrm{~mm}$ diameter rebar at $150 \mathrm{~mm}$ spacing. This figure indicates that for average case scenarios, the safety factor of $600 \mathrm{~mm}$ wall element decreases from 2.54 to 1.95 at year 2013 and to 1.62 at year 2033, respectively. By comparison for worst case scenarios, the safety factor decreases from 2.54 to 1.20 at year 2013 and to 0.58 at year 2033, respectively. Thus, this element does not require immediate strengthening as the safety factor is still greater than 1.0 at year 2013 for both scenarios.

Figure 27 shows the reduction of safety factor for beam element with $500 \mathrm{~mm} \times 800 \mathrm{~mm}$ cross-section and reinforced with $4 \mathrm{D} 28 \mathrm{~mm}$ diameter rebar against flexure. This figure indicates that, for average case scenarios, the safety factor of the beam decreases from 2.46 to 1.94 at year 2013 and to

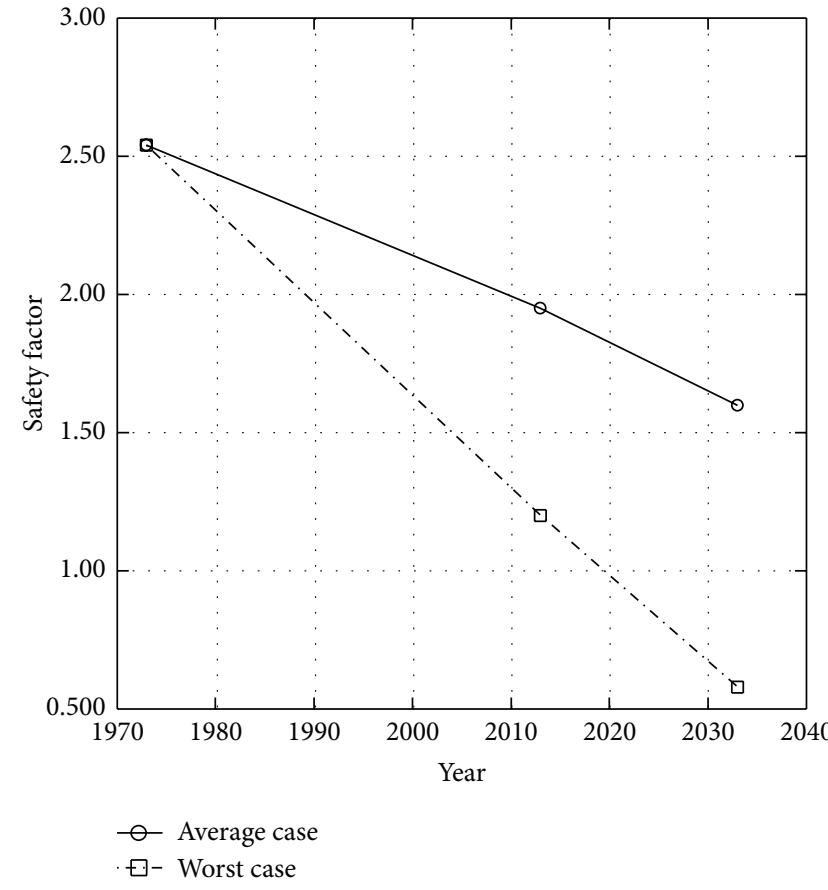

FIGURE 26: Safety factor for wall element with $600 \mathrm{~mm}$ depth and reinforced with $22 \mathrm{~mm}$ diameter rebar at $150 \mathrm{~mm}$ spacing.

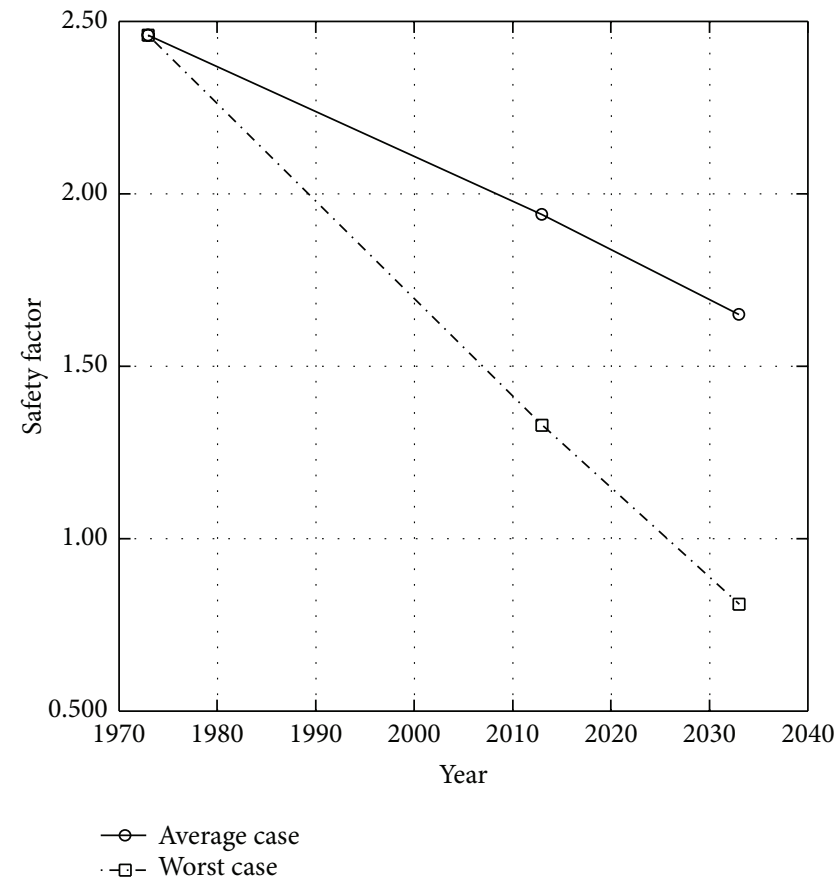

FIGURE 27: Safety factor for beam element with $500 \mathrm{~mm} \times 800 \mathrm{~mm}$ cross-section reinforced with $4 \mathrm{D} 28 \mathrm{~mm}$ diameter rebar against flexure.

1.65 at year 2033, respectively. By comparison, for worst case scenarios, the safety factor decreases from 2.46 to 1.33 at year 2013 and to 0.81 at year 2033, respectively. Thus, this beam does not require immediate strengthening as the safety factor is still greater than 1.0 at year 2013 . 


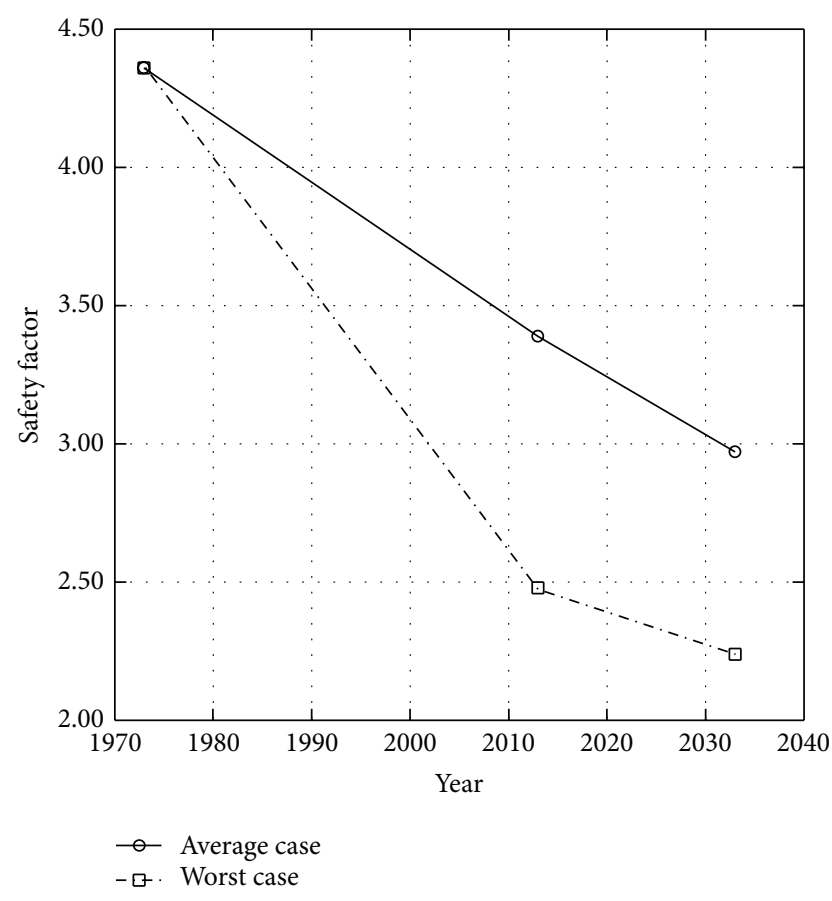

FIGURE 28: Safety factor for beam element with $500 \mathrm{~mm} \times 800 \mathrm{~mm}$ cross-section and shear reinforced with $2 \mathrm{D} 12 \mathrm{~mm}$ diameter rebar with $150 \mathrm{~mm}$ spacing against shear.

Figure 28 shows the reduction of safety factor for beam element with $500 \mathrm{~mm} \times 800 \mathrm{~mm}$ cross-section and shear reinforced with 2D12 mm diameter rebar with $150 \mathrm{~mm}$ spacing against shear. This figure indicates that, for average case scenarios, the safety factor of the beam decreases from 4.36 to 3.39 at year 2013 and to 2.97 at year 2033, respectively. By comparison, for worst case scenarios, the safety factor decreases from 4.36 to 2.48 at year 2013 and to 2.24 at year 2033, respectively. Thus, this beam does not require immediate strengthening as the safety factor is still greater than 1.0 at year 2013 .

It should be mentioned here that the remaining life assessment of concrete structure due to corrosion attack also has some limitations. Some of the models used in the analysis are derived based on idealized condition. For example, the assumption used for corrosion initiation model based on Fick's second law given in (1) may not be in agreement with the actual service conditions. Fick's second law assumes that concrete is homogeneous material and relative in moist condition (saturated). In reality, concrete cover is generally not saturated with water, concrete is a nonhomogeneous material due to the presence of microcracking, interconnected pores, and aggregated particles, and the diffusion coefficient $D$ may change with time due to hydration progress [19]. Therefore, the remaining life assessment of reinforce concrete structure should be combined with engineering judgment and should be validated with the actual field condition. Further, the remaining life assessment should be performed every 510 years as conditions may change significantly than those predicted by available deterioration model.

\section{Conclusions}

The main conclusions drawn from this study can be summarized as follows.

(i) From field and laboratory tests, no significant corrosion activity has been found at CWICS. Most of the reinforcing bars were still in a relatively passive condition as concrete surrounding the reinforcing bars was still in a high alkaline stage. Furthermore, the chloride level at rebar position was found around $0.01 \%$ by weight of concrete. This value was still below chloride threshold level to initiate corrosion given in SNI-03-2847 at $0.025 \%$.

(ii) From compressive test of core-drilled sample, train $\mathrm{A} / \mathrm{B}$ has the lowest average strength of all samples. However, in terms of cover thickness, train A/B has the highest cover thickness of all trains.

(iii) Due to its lowest compressive strength obtained from compression test of core-drilled sample, train A/B has the highest corrosion rate for all trains.

(iv) Based on the available data compiled from the tests, two different scenarios were used to estimate the remaining life of CWICS. Using this approach, the average case scenario represented closer to the actual condition than that of the worst case scenario. The analysis using worst case scenario for train $\mathrm{A} / \mathrm{B}$ gives the remaining capacity of $40 \%$ of the initial capacity. This result does not represent the existing condition of CWICS, which shows no significant sign of distress up to the present. By contrast, using average case scenario for train $\mathrm{A} / \mathrm{B}$ gives the remaining capacity of $83 \%$ of the initial capacity.

(v) Structural analysis shows that the safety factor of most concrete elements of CWICS was still higher than unity up to year 2033. However, fewer elements were also found to have safety factor approach to unity at year 2013. These elements with low safety factor require immediate strengthening to fulfill its intended service life up to 2033.

\section{Conflict of Interests}

The authors declare that there is no conflict of interests regarding the publication of this paper.

\section{Acknowledgments}

The authors greatly acknowledge the support of Material Testing Laboratory of Civil Engineering Diploma Program and the Institute of Research and Community Services of Institut Teknologi Sepuluh Nopember (ITS), during field and laboratory investigation of the study.

\section{References}

[1] A. Neville, "Chloride attack of reinforced concrete: an overview," Materials and Structures, vol. 28, no. 2, pp. 63-70, 1995. 
[2] "Tata Cara Perhitungan Struktur Beton untuk Bangunan Gedung (Indonesia concrete building code)," SNI-03-2847, 2013.

[3] P. K. Mehta, Concrete in the Marine Environment, Taylor \& Francis, New York, NY, USA, 2003.

[4] H. S. Müller, M. Haist, and M. Vogel, "Assessment of the sustainability potential of concrete and concrete structures considering their environmental impact, performance and lifetime," Construction and Building Materials, vol. 67, pp. 321-337, 2014.

[5] DuraCrete, Probabilistic Performance Based Durability Design of Concrete Structures, 2000.

[6] BS-1881:Part203, Recommendations for Measurement of Velocity of Ultrasonic Pulses in Concrete, British Standards Institution, London, UK, 1986.

[7] ACI-Committee-228.1R-03, In-Place Methods to Estimate Concrete Strength Building, American Concrete Institute, Farmington Hills, Mich, USA, 2003.

[8] P. K. Mehta and P. J. M. Monteiro, Concrete: Microstructure, Properties, and Materials, McGraw-Hill, 3rd edition, 2006.

[9] RILEM-Recommendations, "Absorption of water by immersion under vacuum. Materials and structures," in RILEM CPC 11.3, vol. 101, pp. 393-394, 1984.

[10] X. Chen, S. Wu, and J. Zhou, "Influence of porosity on compressive and tensile strength of cement mortar," Construction and Building Materials, vol. 40, pp. 869-874, 2013.

[11] Y. Y. Kim, K. M. Lee, J. W. Bang, and S. J. Kwon, "Effect of W/C ratio on durability and porosity in cement mortar with constant cement amount," Advances in Materials Science and Engineering, vol. 2014, Article ID 273460, 11 pages, 2014.

[12] BS-EN-14630, Products and Systems for the Protection and Repair of Concrete Structures. Test Methods. Determination of Carbonation Depth in Hardened Concrete by the Phenolphthalein Method, British Standards Institution, London, UK, 2006.

[13] M. Shekarchi, F. Moradi-Marani, and F. Pargar, "Corrosion damage of a reinforced concrete jetty structure in the Persian Gulf: a case study," Structure and Infrastructure Engineering: Maintenance, Management, Life-Cycle Design and Performance, vol. 7, no. 9, pp. 701-713, 2011.

[14] ASTM-C-876, "Standard test method for half-cell potentials of uncoated reinforcing steel in concrete," in Annual Book of ASTM Standards, vol. 03.02, pp. 11-16, 2006.

[15] K. A. T. Vu and M. G. Stewart, "Structural reliability of concrete bridges including improved chloride-induced corrosion models," Structural Safety, vol. 22, no. 4, pp. 313-333, 2000.

[16] J. Zhang and Z. Lounis, "Sensitivity analysis of simplified diffusion-based corrosion initiation model of concrete structures exposed to chlorides," Cement and Concrete Research, vol. 36, no. 7, pp. 1312-1323, 2006.

[17] M. G. Stewart and D. V. Rosowsky, "Structural safety and serviceability of concrete bridges subject to corrosion," Journal of Infrastructure Systems, vol. 4, no. 4, pp. 146-155, 1998.

[18] D. A. Jones, "Localized surface plasticity during stress corrosion cracking," Corrosion, vol. 52, no. 5, pp. 356-362, 1996.

[19] J.-K. Kim, C.-Y. Kim, S.-T. Yi, and Y. Lee, "Effect of carbonation on the rebound number and compressive strength of concrete," Cement and Concrete Composites, vol. 31, no. 2, pp. 139-144, 2009. 

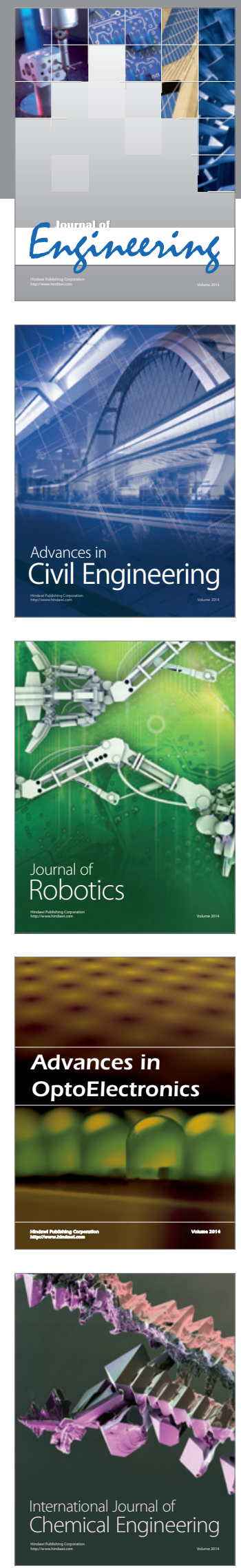

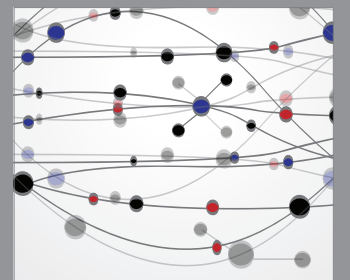

The Scientific World Journal
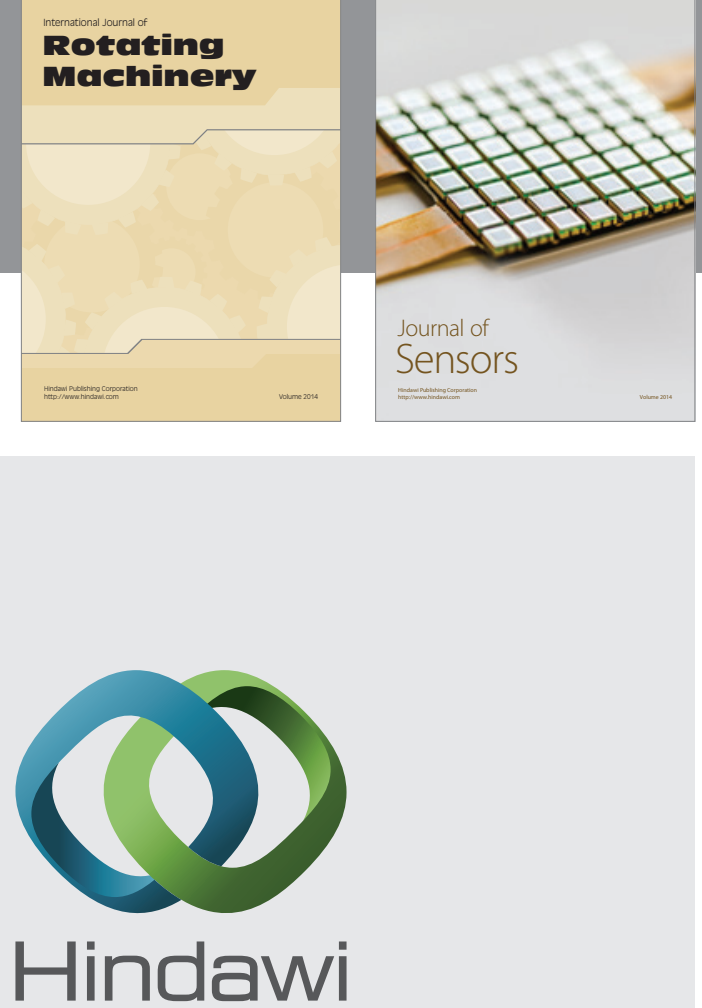

Submit your manuscripts at http://www.hindawi.com
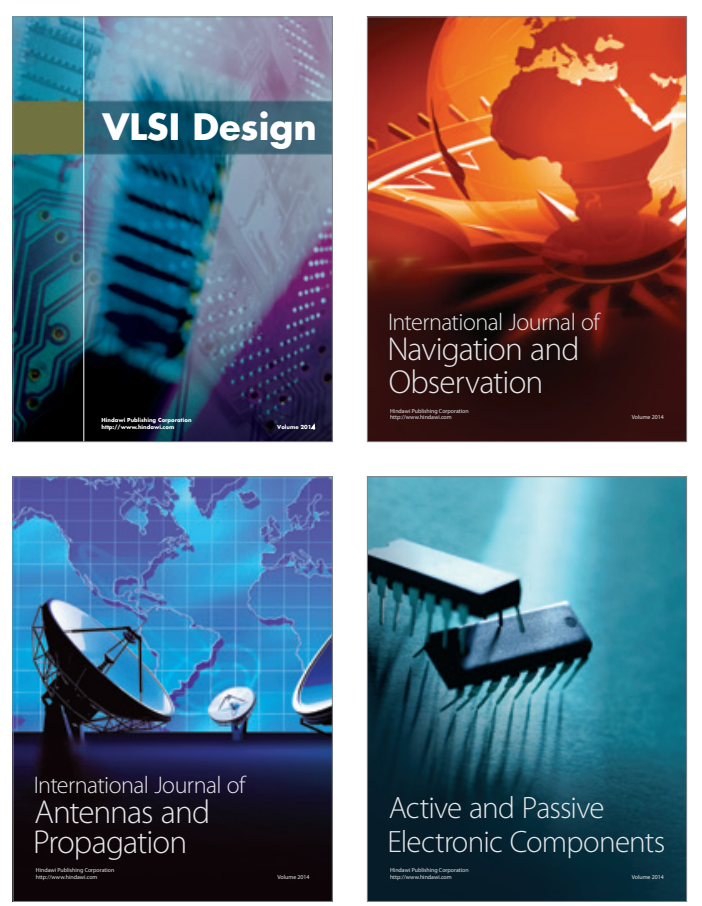
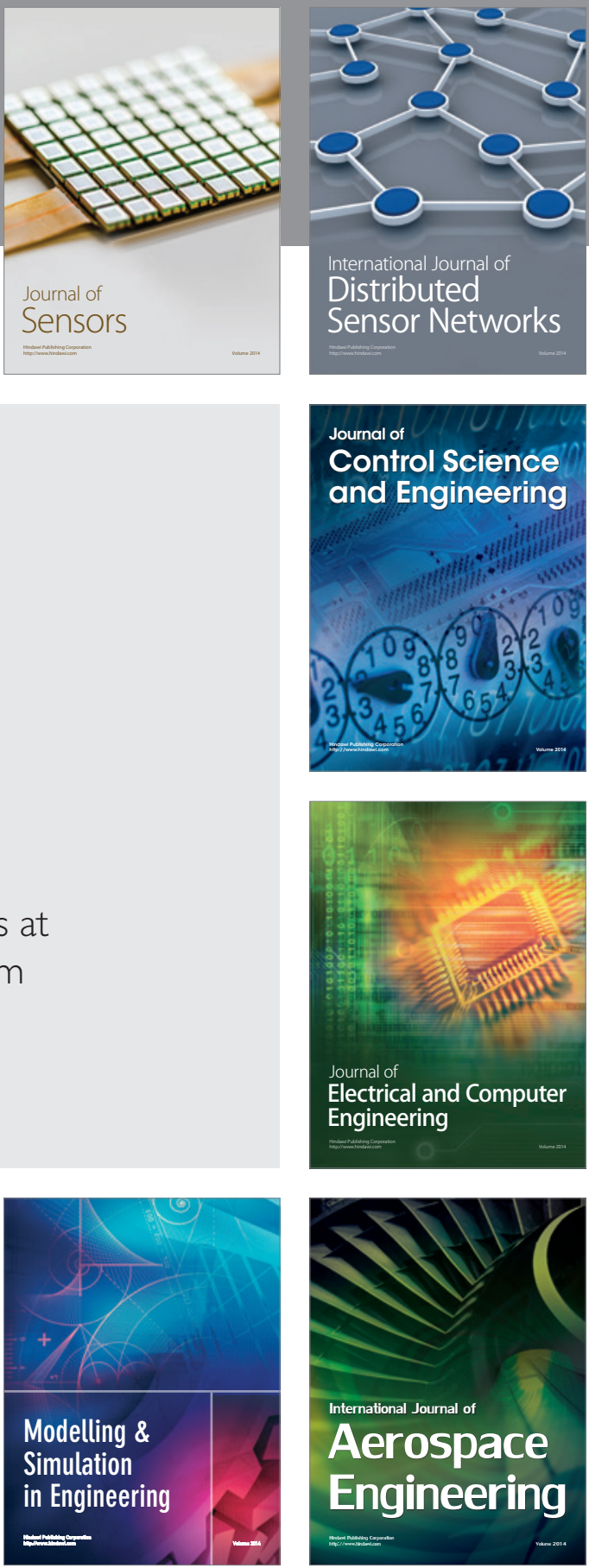

Journal of

Control Science

and Engineering
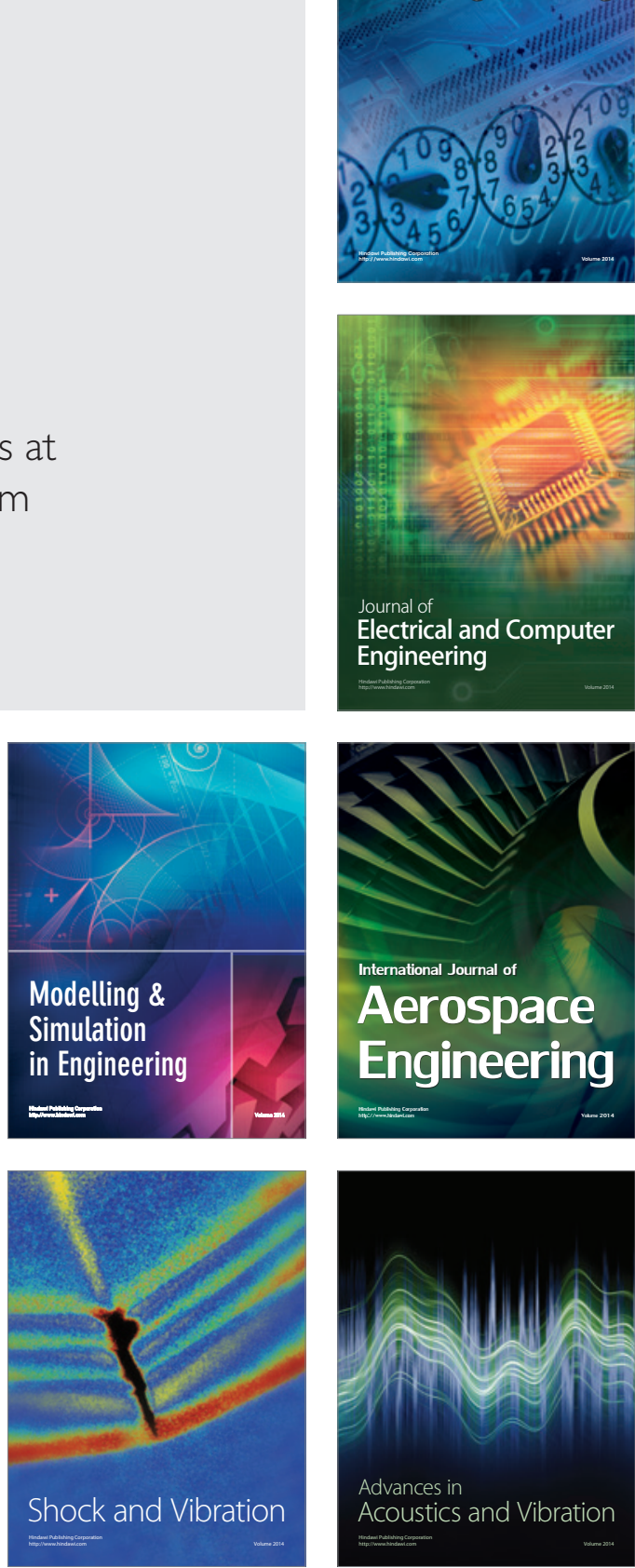